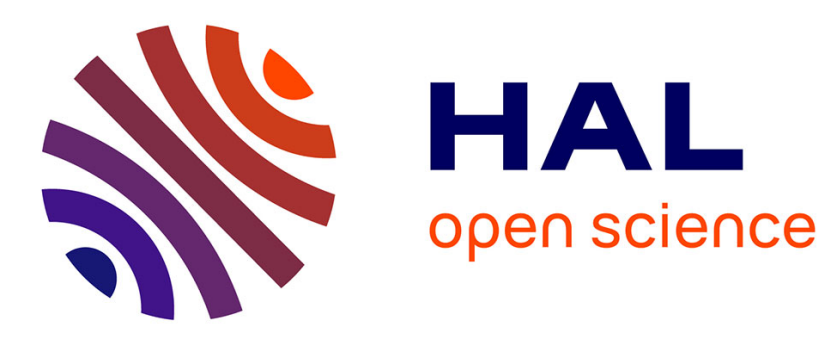

\title{
Mitochondria and apoptosis
}

Bernard Mignotte, Jean-Luc Vayssière

\section{To cite this version:}

Bernard Mignotte, Jean-Luc Vayssière. Mitochondria and apoptosis. European Journal of Biochemistry, 1998. hal-03036312

\section{HAL Id: hal-03036312 \\ https://hal.science/hal-03036312}

Submitted on 18 Dec 2020

HAL is a multi-disciplinary open access archive for the deposit and dissemination of scientific research documents, whether they are published or not. The documents may come from teaching and research institutions in France or abroad, or from public or private research centers.
L'archive ouverte pluridisciplinaire HAL, est destinée au dépôt et à la diffusion de documents scientifiques de niveau recherche, publiés ou non, émanant des établissements d'enseignement et de recherche français ou étrangers, des laboratoires publics ou privés. 


\title{
MITOCHONDRIA AND APOPTOSIS
}

\author{
Bernard MIGNOTTE, Jean-Luc VAYSSIERE \\ UPR9061 du CNRS, EA1636 de l'Université de Versailles/Saint-Quentin \\ and Laboratoire de Génétique Moléculaire de l'EPHE \\ Centre de Génétique Moléculaire, 91198 Gif-sur-Yvette cedex
}

This paper is dedicated to Françoise Mignotte, Maître de Conférences EPHE, deceased on 3 August 1997.

\section{Corresponding author :}

Bernard MIGNOTTE, Centre de Génétique Moléculaire, Centre National de la Recherche Scientifique, F-91198 Gif-sur-Yvette cedex.

Tel : (33) $169823810 \quad$ Fax : (33) 169823150

E-mail : bernard.mignotte@cgm.cnrs-gif.fr

E-mail adress should be published. 


$$
-2 \text { - }
$$


Abbreviations used in this paper : $\Delta \Psi_{\mathrm{m}}$, mitochondrial membrane potential; PCD, programmed cell death; caspases, cystein aspartase; PT, permeability transition; ROS, reactive oxygen species; DEVD, AcAsp-Glu-Val-Asp-CHO; TNF- $\alpha$, tumor necrosis factor- $\alpha$; SOD, superoxide dismutase; NGF, nerve growth factor; NF- $\kappa \mathrm{B}$, nuclear factor$\kappa \mathrm{B}$; AIF, apoptosis inducing factor; Apaf-1, apoptosis protease-activating factor 1; ANT, adenine nucleotides translocase; GSH, glutathione; IL-3, interleukin-3. 


\section{Summary}

Programmed cell death serves as a major mechanism for the precise regulation of cell numbers, and as a defense mechanism to remove unwanted and potentially dangerous cells. Despite the striking heterogeneity of cell death induction pathways, the execution of the death program is often associated with characteristic morphological and biochemical changes, and this form of programmed cell death has been termed apoptosis.

Genetic studies in C. elegans had led to the identification of cell death genes (ced). Ced-3 and ced-4 are essential for cell death. Ced-9 antagonizes the activities of ced-3 and ced-4, and thereby protects cells that should survive from any accidental activation of the death program. Caspases (cystein aspartase) are the mammalian homologues of CED-3. CED-9 protein is homologous to a family of many members termed the Bcl-2 family (Bcl-2s) in reference to the first discovered mammalian cell death regulator. In both worm and mammalian cells, the antiapoptotic members of the Bcl-2 family act upstream of the "execution caspases" somehow preventing their proteolytic processing into active killers.

Two main mechanisms of action have been proposed to connect $\mathrm{Bcl}-2 \mathrm{~s}$ to caspases. In the first one, antiapoptotic Bcl-2s would maintain cell survival by dragging caspases to intracellular membranes (probably the mitochondrial membrane) and by preventing their activation. The recently described mammalian protein Apaf-1 (apoptosis 
protease-activating factor 1) could be the mammalian equivalent of CED-4 and could be the physical link between Bcl-2s and caspases. In the second one, Bcl-2 would act by regulating the release from mitochondria of some caspases activators: cytochrome c and/or AIF (Apoptosis-Inducing-Factor). This crucial position of mitochondria in programmed cell death control is reinforced by the observation that mitochondria contribute to apoptosis signaling via the production of reactive oxygen species. Although for a long time the absence of mitochondrial changes was considered as a hallmark of apoptosis, mitochondria appear today as the central executioner of programmed cell death. In this review, we examine the data concerning the mitochondrial features of apoptosis. Furthermore, we discuss the possibility that the mechanism originally involved in the maintenance of the symbiosis between the bacterial ancestor of the mitochondria and the host cell precursor of eukaryotes, provided the basis for the actual mechanism controlling cell survival.

\section{Key words :}

Programmed cell death / apoptosis / caspases / mitochondria / Bcl-2 


\section{Introduction}

The functions of Programmed Cell Death

Soon after it was recognized that organisms are made of cells, it was discovered that cell death can be an important part of life. First observed during amphibian metamorphosis, normal cell death was soon found to occur in many developing tissues in both invertebrates and vertebrates (Clarke and Clarke, 1996). The term programmed cell death (PCD) was used to describe the cell deaths that occur in predictable places and at predictable times during development, to emphasize that the deaths are somewhat programmed into the development plan of the organism. Subsequently it has been established that PCD also serves as a major mechanism for the precise regulation of cell numbers (Raff, 1992), and as a defense mechanism to remove unwanted and potentially dangerous cells, such as self-reactive lymphocytes (Golstein, 1989), cells that have been infected by viruses (Vaux et al., 1994) and tumor cells (Williams, 1991). In addition to the beneficial effects of PCD, the inappropriate activation of cell death may cause or contribute to a variety of diseases, including acquired immunodeficiency syndrome (AIDS) (Ameisen et al., 1995a), neurodegenerative diseases, and ischemic strokes (Martinou, 1993; Raff et al., 1993). Conversely, a defect in PCD activation could be 
responsible for some auto-immune diseases (Tan, 1994) and is also involved in oncogenesis (Bursch et al., 1992).

Many different signals that may originate either from within or outside a cell have been shown to influence the decision between life and death. These include lineage information, extracellular survival factors or signals, cell interactions, hormones, cell contacts, genotoxic and physical trauma, anoxia, oncogene expression, and immune killing. In contrast to the striking heterogeneity of cell death induction pathways, the execution of the death program is often associated with characteristic morphological and biochemical changes, and this form of PCD has been termed apoptosis (Kerr et al., 1972). Apoptotic hallmarks include membrane blebbing, cell shrinkage, chromatin condensation, DNA cleavage and fragmentation of the cell into membrane-bound apoptotic bodies whose surface expresses potent triggers for phagocytosis. However, it must be kept in mind that although apoptosis is the most common form of PCD, dying cells may follow other morphological types (Clarke, 1990; Schwartz et al., 1993). Moreover, apoptotic cells do not always harbor all cardinal features of their cell death type, in particular DNA cleavage does not appear to be an absolute requirement (SchulzeOsthoff et al., 1994b). Nevertheless, the observation that most cells undergoing PCD change similarly has suggested that apoptosis reflects the operation of an intracellular 
death program that can be activated or inhibited by a variety of physiological or pathological environmental stimuli. The existence of an intrinsic cell suicide program was ascertained through genetic studies in the nematode Caenorhabditis elegans that identified genes involved in the cell death program and its control (Ellis and Horvitz, 1986; Horvitz and Ellis, 1982), and then through the finding that some of these genes were homologous to mammalian genes (Hengartner and Horvitz, 1994; Yuan et al., 1993). These considerations have led to a different meaning of the term PCD: it now refers to any cell death that results from an intracellular death program, no matter what activates it and whatever the changes associated with the destruction of the cell. In this way PCD appears as a critical element in the repertoire of potential cellular responses, as are cell differentiation, quiescence or proliferation. Moreover, these studies demonstrated the very early occurrence of PCD in the course of metazoan evolution and the substantial conservation of its basal machinery from nematodes to humans.

The death program and its intracellular control

All nucleated mammalian cells, both in developing and mature organs, are able to undergo PCD (Ishizaki et al., 1995; Weil et al., 1996) and constitutively express all the protein components required to execute the death program (Jacobson et al., 1994), which 
are normally suppressed by extracellular survival signals. Genetic experiments in both $C$. elegans and Drosophila melanogaster suggest that the death program is also expressed constitutively in invertebrate cells (Shaham and Horvitz, 1996; Steller, 1995), making it likely that this is a basic feature of all metazoan nucleated cells. Moreover, it seems that new macromolecular synthesis, when necessary for PCD, contributes to the activation rather than to the execution of the death program (Raff, 1992; Weil et al., 1996).

The programmed cell death cascade can be conveniently divided into several phases. During the activation phase, multiple signaling pathways lead from the various death-triggering signals to the central control of the cell death machinery and activate it. This is followed by the execution stage, in which the activated machinery acts on multiple cellular targets, and, finally, the destruction phase in which the dead or dying cell is broken down.

A most important clue to the molecular nature of the death program came initially from genetic studies in C. elegans that led to the identification of a dozen cell death genes (ced) that are responsible for one aspect or another of cell death processes (Ellis et al., 1991). Three of these genes stand out. Two, ced-3 and ced-4 are essential for cell death. The third, ced-9, antagonizes the death activities of $c e d-3$ and $c e d-4$, and thereby protects cells that should survive from any accidental activation of the death program. Moreover, 
genetically, ced-4 had been placed between ced-9 and ced-3 in the pathway leading to cell death, suggesting that CED-4 might act as an adaptator, linking the upstream regulator CED-9 to the downstream death effector CED-3 (Shaham and Horvitz, 1996). Spectacular progress arose with their cloning, when it became clear that they encoded components of a universal and highly conserved death machinery (Table 1). CED-3 protein turned out to be a member of a family of cysteine proteases, known as caspases. Indeed, identification of CED-3 as a caspase homologue was the first evidence of this family's involvement in PCD (Yuan et al., 1993). The mammalian caspase family now comprises at least ten known members, most of which have been definitively implicated in PCD (Duan et al., 1996; Fraser and Evan, 1996; McCarthy et al., 1997). All cleave their substrates after specific aspartic acids and are themselves activated by cleavage at specific aspartic acids inasmuch as their proteolytic processing is required to convert the inactive zymogen present in the living cell into the fully active killer enzyme form. In vitro experiments suggest that some caspases could activate themselves, and some could activate other caspases, acting in a proteolytic cascade (Nicholson and Thornberry, 1997). Caspases mediate PCD by cleaving selected intracellular proteins, including proteins of the nucleus, nuclear lamina, cytoskeleton, endoplasmic reticulum, and cytosol. However, which of these targets is, if any, responsible for the cell blebbing, condensation and 
fragmentation that characterize PCD is unknown. As specific protein or peptide caspase inhibitors can block PCD in all animal and invertebrate cells and in most if not all cell death inducing conditions that have been tested, it seems likely that caspases form the core of the death program.

CED-9 protein is homologous to a family of many members termed the Bcl-2 family in reference to the first discovered mammalian cell death regulator (Reed, 1997). Some members, such as Bcl-2 or Bcl- $\mathrm{x}_{\mathrm{L}}$, inhibit PCD, whereas others, such as Bax and Bik, promote cell death (Table 1). The various family members (referred to here as Bcl2 s), which are primarily localized to intracellular membranes, can dimerize with one another, with one monomer antagonizing or enhancing the function of the other. In this way, it is assumed that the ratio of activators to inhibitors in a cell could determine the propensity of the cell to undergo PCD (Korsmeyer, 1995). Recent reports provide spectacular advancements in the understanding of the mechanism of action of these proteins. It was shown that, in both worm and mammalian cells, the antiapoptotic Bcl-2s act upstream of the "execution caspases" somehow preventing their proteolytic processing into active killers (Golstein, 1997; Shaham and Horvitz, 1996). How these proteins perform this feat remains unknown although two main mechanisms of action have been proposed to connect Bcl-2s to caspases. 
In the first one, antiapoptotic Bcl-2s would maintain cell survival by dragging caspases to intracellular membranes and in this way by preventing their activation (Chinnaiyan et al., 1997b; Wu et al., 1997). This model arose from the elucidation of the role of the somewhat mysterious CED-4 protein (Hengartner, 1997). Indeed, it was first shown that CED-4 can interact directly and simultaneously with both CED-9 and CED3, pointing to a model in which CED-9 prevents cell death by directly binding to a CED3/CED-4 complex, keeping it in an inactive conformation (Chinnaiyan et al., 1997b; Wu et al., 1997). Subsequently, it has been established that CED-4, acting as a contextdependent ATPase, promotes CED-3 autoprocessing (Chinnaiyan et al., 1997a). These observations, concerning developmental cell death in C. elegans, were extended to mammalian PCD (Chinnaiyan et al., 1997b). The recently described apoptosis proteaseactivating factor 1 (Apaf-1), a component required for dATP-induced caspase-3 activation in a cell-free system, could be the mammalian equivalent of CED-4 (Hofmann et al., 1997; Zou et al., 1997).

Two separate lines of evidence suggested that Bcl-2 would also act by regulating the release of some caspases activators usually sequestered in intracellular compartments (Kluck et al., 1997a; Susin et al., 1996; Yang et al., 1997). On the one hand, it was shown that some Bcl-2s have pore-forming properties raising the possibility that these products 
can regulate the permeability of the intracellular membranes (Minn et al., 1997; Muchmore et al., 1996; Schendel et al., 1997). On the other hand, several reports established that activation of "execution caspases" required the preliminary shift to the cytosol of regulatory components, namely cytochrome c or AIF (Apoptosis-InducingFactor), previously sequestered in mitochondria (Kluck et al., 1997a; Krippner et al., 1996; Susin et al., 1996; Yang et al., 1997). The protective effect of Bcl-2 was linked to its ability to prevent the release of these proteins.

These distinct and probably independent links between Bcl-2 and caspases match with the apparent redundancy of caspases and the existence of several alternative activation pathways that seem to be the rule for mammalian cell death. The multiplicity of caspases illustrates this complexity. Although caspases appear as the key components of the execution machinery of the cell death program, they also intervene in the death signal transduction cascade in some PCD, such as those triggered by surface receptor activation (Nagata, 1997). These different possible pathways of caspase activation would be consistent with the previously described possibility for some caspases to be activated by autoprocessing and for others to require transcleavage (the proteolytic cascade).

Given the complexity and diversity of caspase activation pathways, these experiments point to the mitochondrion as an unifying element of PCD. An irony in the 
story of PCD studies, for a long time the absence of mitochondrial changes was considered as a hallmark of PCD (Kerr and Harmon, 1991) while, conversely, mitochondria are now sometimes presented as the central executioner of PCD (Golstein, 1997; Kroemer et al., 1997; Reed, 1997). This crucial position of mitochondria in PCD control is reinforced by the results obtained from distinct approaches establishing that mitochondria can contribute to PCD via the production of cell death signaling ROS. This review examines the data concerning the mitochondrial features of PCD with the aim to reach an equilibrated view of the involvement of mitochondria in cell death control and progress. 


\section{Production of reactive oxygen species by mitochondria and apoptosis}

First evidence suggesting the involvement of mitochondria in cell death arose from the study of the Tumor Necrosis Factor- $\alpha($ TNF- $\alpha)$-induced cytotoxicity (Lancaster et al., 1989; Schulze-Osthoff et al., 1992). Indeed, an alteration of the mitochondrial function was associated with the early phases of the cell death and was defined as a crucial step of the process. The observed inhibition of the mitochondrial respiratory chain was assumed to result in the over production of Reactive Oxygen Species (ROS) which would act as mediators of the death signaling pathway (Schulze-Osthoff et al., 1993).

ROS as mediators of PCD

ROS, such as superoxide anion, hydrogen, organic peroxides and radicals, are generated by all aerobic cells as byproducts of a number of metabolite reactions and in response to various stimuli (Fridovich, 1978). Mitochondria are believed to be a major site of ROS production: superoxide radical is produced by a single electron transfer to molecular oxygen at the level of the respiratory chain, mainly at the ubiquinone site in complex III. However, endoplasmic reticulum and nuclear membranes also contain $\mathrm{e}^{-}$ transport chains that can lose $\mathrm{e}^{-}$and generate superoxide radical. Some fatty acid metabolites, such as those derived from arachidonic acid by the lipoxygenase pathway, 
are also ROS. However, ROS play a role in physiological systems : they were shown to be responsible for the inducible expression of genes associated with inflammatory and immune responses. Current evidence indicates that different stimuli use ROS as signaling messengers to activate transcription factors, such as AP-1 and nuclear factor- $\kappa \mathrm{B}(\mathrm{NF}-\kappa \mathrm{B})$, and induce gene expression (Pinkus et al., 1996).

The ability of oxidative stress, which is an excessive production of ROS, to provoke necrotic cell death as a result of massive cellular damages associated to lipid peroxidation and alterations of proteins and nucleic acids, is well documented for a long time (Halliwell and Gutteridge, 1989). The highly reactive hydroxyl radical $(\cdot \mathrm{OH})$, byproduct of superoxide anion or hydrogen peroxide, is assumed to be directly responsible for most of the oxidative damages leading to the non-physiological necrosis (Halliwell and Gutteridge, 1990). To prevent oxidative damage, mammalian cells have developed a complex antioxidant defense system that includes nonenzymatic antioxidants (e.g. glutathione, thioredoxine) as well as enzymatic activities (e.g. catalase, superoxide dismutase (SOD)) (Sies, 1991). In this point of view, aerobic cells appear as being under a continual "oxidative siege", their survival depending on a balance between ROS and antioxidants. On the other hand, the possible implication of ROS as signaling molecules in more physiological deaths such as PCD is an emerging concept. Thus, since the initial 
observation outlining the contribution of ROS to the TNF- $\alpha$-induced cytotoxicity, there is mounting evidence that these compounds may be central in the cell death transduction pathways. Indeed, several observations suggest that ROS might mediate PCD: 1) the addition of ROS or the depletion of endogenous antioxidants can promote cell death (Guénal et al., 1997; Kane et al., 1993; Lennon et al., 1991; Ratan et al., 1994; Sato et al., 1995), 2) PCD can sometimes be delayed or inhibited by antioxidants (Greenlund et al., 1995; Mayer and Noble, 1994; Mehlen et al., 1996; Sandstrom and Buttke, 1993; Wong et al., 1989) and 3) increases in intracellular ROS are sometimes associated with PCD (Martin and Cotter, 1991; Quillet-Mary et al., 1997; Uckun et al., 1992). Moreover, it was shown that Bcl-2 may act in an antioxidant pathway to block a putative ROSmediated step in the cascade of events required for PCD (see below). So, in addition to their role in TNF- $\alpha$-induced killing, the contribution of ROS to the activation of the execution machinery was extended to PCD triggered by a wide range of influences including UV light, ionizing irradiation, anthracyclines, ceramides, glucocorticoids or survival-factor withdrawal (see (Jacobson, 1996). Moreover some data raise the possibility that ROS are also required for the execution of the death program (Kroemer et al., 1995). However, they must be cautiously considered inasmuch as, in the majority of these systems, it is difficult to ascertain that the observed ROS accumulation 
corresponds to a causal effect and is not a side effect of the other changes accompanying the killing process. Moreover, in these cases, ROS increase most often arises during the later stage of the death program, i.e. during the destruction phase when the cell is broken down, and may be associated with a necrotic type terminal degradation of the cell. Exogenous sources of ROS such as hydrogen peroxide can induce PCD or necrosis depending upon the dose added (Guénal et al., 1997). So a burst in ROS, in response to a dramatic perturbation of the physiology of the dying cell, could convert the late PCD steps into necrotic death. Therefore, it appears that at any moment the level of intracellular ROS can determine the fate of the cell: low levels of ROS can induce PCD while accumulation of high levels promotes necrosis or can lead PCD-committed cells toward necrotic-like destruction.

\section{PCD-mediating ROS are produced by mitochondria}

The nature of the ROS involved in PCD is a conflicting question that will allow us to return to the central subject of this review, i.e. the role of mitochondria in PCD. Indeed, two opposite models have emerged concerning the source of signaling ROS, in relation with the variety of metabolic reactions and intracellular sites which can generate ROS (see above) (Jacobson, 1996). While most investigators believe that oxidants are 
produced by electron chain transport, some data seem to moderate this point of view. Fatty acid metabolites, such as those produced from arachidonic acid by the lipoxygenase pathway, may be better mediators of PCD (O'Donnell et al., 1995). On the one hand, it is argued that these molecules harbor a more specific reactivity than superoxide anion and its by-products, this biological specificity being assumed necessary for a signaling role in PCD transduction pathways. On the other hand, it was shown that exogenous fatty acid metabolites can promote PCD and that, in some cases, their increased production was associated with cell death. It must be underlined that such a situation is limited to systems where the death signal result is mediated by surface receptors. Nevertheless, these considerations do not refute the compelling evidence of the involvement of electron transport chain-produced ROS in cell death signaling. It appears more reasonable to consider that, depending upon the cell death stimulus and the cell model, these two types of ROS can mediate PCD or even both contribute to the activation of the execution machinery as suggested by studies of TNF- $\alpha$-induced PCD.

Where are localized the electron transport chains that produce cell death signaling ROS such as hydrogen peroxide? The question must address distinct intracellular compartments as reticulum endoplasmic, nuclear layer and especially mitochondria. The more convincing responses have arisen from indirect studies measuring the consequences 
of an alteration of the electron transport chain on the PCD process. In this way, it was established that both ROS accumulation and PCD process require the presence of a functional mitochondrial respiratory chain in most ROS-dependent cell death systems (Higuchi et al., 1997; Quillet-Mary et al., 1997; Schulze-Osthoff et al., 1993; Sidoti-de Fraisse et al., 1997). Indeed, it was shown that an upstream inhibition, with chemical compounds acting on complex I (Quillet-Mary et al., 1997; Schulze-Osthoff et al., 1992), or an elimination of the electron transfer chain (Higuchi et al., 1997; Schulze-Osthoff et al., 1993; Sidoti-de Fraisse et al., 1997), by depletion of the mtDNA, prevent ROS accumulation and consequently protect cells against PCD. Another indirect argument is provided by the scavenger role of mitochondrial glutathione in the regulation of ROSmediated PCD (Goossens et al., 1995). The ubiquinone site in complex III appears as the major site of mitochondrial ROS production as this site catalyzes the conversion of molecular oxygen to superoxide anion which can lead to the formation of other potent ROS such as hydrogen peroxide and hydrogen radicals. Such a model is supported by the observed potentiation of cell death processes in ROS-dependent PCD when electron flow was inhibited distal to the ubiquinone pool. 


\section{Mechanisms of ROS signaling}

The involvement of mitochondrial ROS in some cell death transduction pathways next leads to the fundamental questions concerning, on the one hand, the causal event of the increased ROS generation and, on the other hand, the molecular mechanisms underlying the ROS signaling. Two viewpoints must first be considered to address the question of the origin of ROS accumulation, which can indeed result from an increased production or from a reduced scavenging by the cellular detoxifying systems. Much of the available data converge to the hypothesis that ROS increases are the consequence of an impairment of the mitochondrial respiratory chain (Gudz et al., 1997; Quillet-Mary et al., 1997; Schulze-Osthoff et al., 1992). In agreement with the above considerations, the observed alterations are distal to the ubiquinone site of the complex III, but the origin of these electron flow disturbances are not clear. The only strong evidence comes from the study of ceramide-induced PCD, in which an increased $\mathrm{H}_{2} \mathrm{O}_{2}$ production was linked to mitochondrial $\mathrm{Ca}^{2+}$ homeostasis perturbation as inhibition of the mitochondrial $\mathrm{Ca}^{2+}$ uptake was shown to abolish both ROS accumulation and cell death (Gudz et al., 1997; Quillet-Mary et al., 1997). However, the recently observed shift of cytochrome c from mitochondria to cytosol in the early phases of many PCD (see below) could provide a 
clue to resolve this question (Kluck et al., 1997a; Liu et al., 1996; Yang et al., 1997). Indeed, the release of cytochrome c must lead to a breakdown of the mitochondrial electron flow downstream of the ubiquinone site which in turn would result in an increased generation of ROS. Such a model is supported by the described correlation between loss of cytochrome $\mathrm{c}$ in respiratory failure in a Fas-induced PCD model (Krippner et al., 1996).

Beside the question of the process of mitochondrial ROS accumulation, arises the problematic concerning the targets of these compounds or more precisely: how can they mediate PCD? Two models can be proposed to approach this conflicting and not well documented subject. The first model assumes that ROS themselves are signaling molecules which activate some crucial components of the PCD machinery. Conversely, the alternative proposition suggests that ROS can act indirectly by modifying the cellular redox potential, which would regulate some key regulatory proteins involved in PCD. Several lines of evidence confirmed by much of the available data agree with an explanation based on indirectly mediated action. First, unlike fatty acid metabolites which harbor specific reactivity and are known to mediate particular signals from surface receptors, mitochondrial ROS are characterized by a lack of biological specificity or even an extreme reactivity, as for the hydroxyl radical: these are all features contrary to the 
requirements of a specific signaling role (Jacobson, 1996). In this way, a direct influence of ROS on PCD process would be correlated to a general damaging effect on cellular structures resulting in necrotic cell death, or perhaps to a more limited action on mitochondria, their site of production, which in turn could activate some mitochondriadependent downstream cascades leading to PCD. Secondly, despite the compelling evidence of the role of mitochondrial ROS in PCD signaling pathways, the prevalent idea is nevertheless that they do not represent a general mediator of cell death, as suggested by the ability of some PCD to occur in very low oxygen environments (Jacobson and Raff, 1995; Shimizu et al., 1995). However, an alternative approach to this problematic would be to consider that the major effect of an increased ROS production is the subsequent decreased availibility of intracellular antioxidants as NADH, NADPH or glutathione (GSH), leading to imbalance of redox status which would be the central common effector of PCD. Anti-Fas/APO-1 antibody or interleukin-3 (IL-3) withdrawalinduced PCD represent good illustrations of this model (Bojes et al., 1997; van den Dobbelsteen et al., 1996). Indeed, no ROS accumulation can be measured in these two systems and anareobic cultured cells deprived of IL-3 still undergo PCD (Schulze-Osthoff et al., 1994a; Shimizu et al., 1995). However, an oxidative stress can be shown in these models as a depletion of glutathione (GSH), a non-enzymatic cellular antioxidant, as a 
result of a rapid and specific efflux of glutathione, an event that takes place at the very beginning of the apoptoptic process (Bojes et al., 1997; van den Dobbelsteen et al., 1996). Moreover, it has been shown that Bcl-2 can protect cells from PCD by shifting the cellular redox potential to a more reduced state (see below). However, the observation that oxidation of thiols other than glutathione can mediate induction of PCD suggest that the intracellular thiol redox status would be the real key factor of the cell death signaling pathways (Kane et al., 1993; Marchetti et al., 1997; Mirkovic et al., 1997; Sato et al., 1995). In this model, the redox state of glutathione or other cellular antioxidants such as thioredoxine, would be in equilibrium with that of thiols resident in some redox sensitive crucial components of the execution machinery (Kroemer et al., 1997). Where does ROS fit this thiol hypothesis? In this putative model, an increased production of mitochondrial ROS would result, either by a direct modification of the thiols or indirectly via a depletion of the intracellular antioxidant pool, in a shift of the redox state of the sensor SH groups to a more oxidized state. The nature of the ROS and the level of the intracellular antioxidant defenses would determine in which way regulatory components are activated to commit cells to PCD. 


\section{Mitochondrial membrane potential, permeability transition and}

\section{apoptosis}

A decrease in mitochondrial membrane potential is an early universal event of apoptosis

Several changes in mitochondrial biogenesis and function are associated with the

commitment to apoptosis. A fall of the membrane potential $(\Delta \Psi \mathrm{m})$ occurs before the fragmentation of the DNA in oligonucleosomal fragments (Petit et al., 1995; Vayssière et al., 1994; Zamzami et al., 1995b). This drop of $\Delta \Psi_{\mathrm{m}}$ is responsible for a defect of maturation of mitochondrial proteins synthesized in the cytoplasm (Mignotte et al., 1990), cessation of mitochondrial translation and an uncoupling of the oxidative phosphorylations (Vayssière et al., 1994). The drop of $\Delta \Psi_{\mathrm{m}}$ has also been observed during apoptosis of thymocytes induced by dexamethasone (Petit et al., 1995), during apoptosis induced by activation of peripheral $\mathrm{T}$ cells, $\mathrm{T}$ hybridomas and pre-B cells (Zamzami et al., 1995a; Zamzami et al., 1995b), during apoptosis of U937 or HeLa cells induced by TNF- $\alpha$ (Marchetti et al., 1996; Sidoti-de Fraisse et al., 1997), or during apoptosis of the neurons deprived of nerve growth factor (NGF) (Marchetti et al., 1996). It is therefore detectable whatever the apoptosis induction signal, physiological (absence of growth factor, glucocorticoids, TNF) or non-physiological (irradiation, chemotherapy). 
Therefore, it seems that the drop of $\Delta \Psi_{\mathrm{m}}$, an event that can be slowed down by cyclosporine A, is a universal characteristic that accompanies apoptosis, independently of the induction signal and of the cellular type (Kroemer et al., 1995). These data show on the one hand that the nuclear fragmentation is a late event as compared to the drop of the $\Delta \Psi_{\mathrm{m}}$ and, on the other hand, that this drop marks the point of no-return of a cell condemned to die. The measure of $\Delta \Psi_{\mathrm{m}}$ allows identification of cells in "pre-apoptosis", including in circulating T lymphocytes from human immunodeficiency virus-1 (HIV-1) carriers (Macho et al., 1995).

Direct interventions on the mitochondrial permeability transition modulate apoptosis

What is the mechanism involved in $\Delta \Psi_{\mathrm{m}}$ disruption? The permeability transition (PT) is a phenomenon that is characterized by the opening of pores in the inner membrane of mitochondria and by its sensitivity to very low concentration of cyclosporin A. These pores, permeable to compounts of molecular mass up to $1500 \mathrm{Da}$ are formed under specific conditions. The opening of these PT pores allows the equilibration of ions and respiratory substrate between cytosol and mitochondrial matrix leading to a reduction of the $\Delta \Psi_{\mathrm{m}}$ and the arrest of ATP synthesis (Bernardi et al., 1992; Petronilli et al., 1994). Interestingly, permeability transition has properties of self-amplification. Indeed, the drop 
of the $\Delta \Psi_{\mathrm{m}}$, that is linked to depletion of non-oxidized glutathione (Macho et al., 1997) and that result from the opening of the PT pores would increase the permeability transition in a retrograde manner (Ichas et al., 1997). We have therefore proposed that the opening of the PT pore may constitute an irreversible state of the effector phase of apoptosis and could account for the apparent synchronization in the drop of $\Delta \Psi_{\mathrm{m}}$ that takes place simultaneously in all the mitochondria of a same cell (Kroemer et al., 1995). The molecular composition of these PT pores is not entirely known. The peripheral benzodiazepin receptor, that has recently been implicated in the protection against ROS (Carayon et al., 1996), and the translocase of adenine nucleotides (ANT) are probable components of the PT pore. Indeed, protoporphyrine IX (that is a ligand of the benzodiazepin recptor), atractyloside (that bind to the external domains of the ANT) and bonkrekic acid (that bind to its matrix side) are able to regulate the opening of PT pores. These last two molecules could favor different conformations of the ANT: an open conformation induced by atractyloside involved in pore opening and a closed conformation stabilized by bongkrekic acid. The drop of $\Delta \Psi_{\mathrm{m}}$ induced by the protoporphyrine IX entails apoptosis (Zamzami et al., 1996a). On the contrary, N-methyl Val-4-cyclosporin A (a derivative of cyclosporine that is not immunosuppressor) and bongkrekic acid, prevent the drop of the mitochondrial potential and the consecutive 
fragmentation of the DNA. These data strongly suggest that the induction of PT provokes apoptosis while its inhibition provides a protection against it. Altogether, these results sustain the hypothesis that the opening of PT pores is involved in the disruption of $\Delta \Psi_{\mathrm{m}}$ observed during the effector phase of apoptosis (Kroemer et al., 1995; Kroemer et al., 1997; Petit et al., 1996).

Mitochondria undergoing permeability transition liberate the pro-apoptotic factor AIF.

Direct alterations of mitochondria can induce apoptosis (Hartley et al., 1994; Wolvetang et al., 1994). The links between mitochondrial perturbations and nuclear alterations can be studied by means of an acellular system where purified nuclei and purified mitochondria are confronted (Newmeyer et al., 1994). Such a system allows on the one hand to study reciprocal and direct effects of one organelle on another and, on the other hand, to characterize at the biochemical level the factors involved. The result of such experiments has shown that, when mitochondria are treated with substances capable to induce PT pores opening, they provoke nuclear apoptosis (condensation of the chromatin and fragmentation of the DNA) (Zamzami et al., 1996b). A strict correlation between induction of the PT and nuclear apoptosis has been observed by using a variety of known inductors of the PT such as atractyloside, pro-oxidants, calcium, protonophores 
and substances that provoke linkage of thiol groups such as diamide. These substances, that have no direct effect on nuclei in absence of mitochondria, confer pro-apoptotic properties upon mitochondria. The pro-apoptotic character (induction of nuclear apoptosis) of the mitochondria treated with atractyloside is altered by inhibitors of the PT such as bongkrekic acid, cyclosporine $\mathrm{A}$ and substances like monochlorobimane that block the cross-linking of the thiols. Cyclosporine A can be replaced by its nonimmunosuppressor analogue, N-methyl Val-4-cyclosporine A, which shows that its inhibitory effect on PT and nuclear apoptosis is independent from its calcineurine activity. These results suggest the implication of the PT pores opening in the regulation of apoptosis induced via the mitochondria.

Finally, mitochondria isolated from apoptotic cells in vivo are capable of inducing nuclear apoptosis in the acellular system. Indeed, the induction of mouse hepatocyte apoptosis in vivo by a combination of D-galactosamine and lipopolysaccharide entails the reduction of $\Delta \Psi_{\mathrm{m}}$. The mitochondria isolated from these cells provoke apoptosis of HeLa cell nuclei in vitro. A similar result has been obtained with mitochondria isolated from cells of spleen processed with dexamethasone. These results show that mitochondria can effectively control nuclear apoptosis (Zamzami et al., 1996b). The mitochondria that undergo the PT would liberate a protein ("Apoptosis Inducing Factor" or AIF) capable of 
inducing nuclear apoptosis. The "apoptogenic" protein derived from the mitochondria is a protease (or a protease-activating protein) of approximately $50 \mathrm{kDa}$ which is capable to activate a caspase-3-like protease (Susin et al., 1996).

\section{Release of cytochrome c by mitochondria and apoptosis}

Another mitochondrial killer component has been demonstrated through the role of cytochrome $\mathrm{c}$ in PCD. Indeed, translocation of cytochrome $\mathrm{c}$ from mitochondria to cytosol has been shown to be a crucial step in the activation of the PCD machinery in various death models, including Fas-, UV-, staurosporine or etoposide-treated mammalian cells, in a cell-free system using Xenopus egg extracts or dATP-primed cytosols of growing cells (Kluck et al., 1997a; Krippner et al., 1996; Liu et al., 1996; Yang et al., 1997). Shift of cytochrome c requires pre-activated cytosolic factors and is blocked by overexpression of Bcl-2. Once released, cytochrome c, in interaction with at least one other cytoplasmic component, initiates the activation of the "execution caspases" which leads to the subsequent characteristic features of apoptosis, including chromatin condensation and nuclear fragmentation, cleavage of fodrin, PARP and Lamin $\mathrm{B}_{1}$. Activated caspases resemble the mammalian CPP32 subfamily in the sense that CPP32 itself is processed and the tetrapeptide DEVD (AcAsp-Glu-Val-Asp-CHO), a 
specific inhibitor of these family members, prevents all cytochrome c-initiated apoptotic events.

Cytochrome $\mathrm{c}$ is an essential component of the mitochondrial respiratory chain: it accepts an electron from cytochrome c reductase and passes it on to cytochrome c oxidase. It is a soluble protein that is located in the intermembrane space and is loosely attached to the surface of the inner mitochondrial membrane. Cytochrome $\mathrm{c}$ is translated on cytoplasmic ribosomes as apocytochrome $\mathrm{c}$ and follows a unique pathway into mitochondria that does not require the signal sequence, electrochemical potential and general protein translocation machinery (Mayer et al., 1995). The apoprotein, on entry into the intermembrane space, gains an heme group, to become the fully folded holocytochrome c. This globular, positively charged protein can no longer pass through the outer mitochondrial membrane and is thought to become electrostatically attached to the inner membrane. How this molecule might act, once released, is still largely unknown. Nevertheless, it has been shown that both the polypeptide chain and the heme prosthetic group of cytochrome $\mathrm{c}$ are required to activate caspases. Moreover, its redox activity, which is essential for its function in oxidative phosphorylation, seems not to be required for its pro-apoptotic activity. 
Cytochrome c as a regulator of "execution caspase" activation

However, a major advance in the understanding of caspase activation has come from the recently established sequence of one component, the apoptosis proteaseactivating factor 1 (or Apaf-1) which, in combination with cytochrome c (Apaf-2) and another cytosolic factor (Apaf-3), is required to promote caspase-3 processing in an apoptotic cell-free extract system (Zou et al., 1997). Remarkably, part of the sequence of Apaf-1 shows a striking similarity to that of CED-4, with the two proteins aligning over most of the CED-4 sequence. In particular, the amino terminus of Apaf-1 probably constitutes a caspase-recruitment domain (CARD), which is found in a number of cell death proteins, including CED-4 and CED-3, and may bind directly to caspases (Hofmann et al., 1997). CED-4, acting as a context-dependent ATPase, promotes CED-3 autoprocessing (Chinnaiyan et al., 1997a) and, in mammalian cells, a CED-4-like activity could act as a bridge between $\mathrm{Bcl}-\mathrm{x}_{\mathrm{L}}$ and caspases with large prodomains, like caspases1 and -8 (Chinnaiyan et al., 1997b). Therefore, Apaf-1 could be this mammalian equivalent of CED-4. However, Apaf-1 could be more sophisticated than CED-4 as a putative protein-protein interactions domain has been identified in the carboxy terminus of the protein. This large domain, absent from CED-4, could be involved in the observed 
physical interaction between Apaf-1 and cytochrome c. In this model, the binding of the released cytochrome $\mathrm{c}$ to Apaf-1 would result in activation of the downstream caspase or in relief of an intrinsic inhibitory activity.

Release of cytochrome $c$ as a result of a perturbation of mitochondrial membrane permeability

The mechanism by which cytochrome $\mathrm{c}$ is released from mitochondria is largely unknown. The recently described pore-forming properties of some Bcl-2s, such as Bcl-2, Bcl- $\mathrm{X}_{\mathrm{L}}$ and Bax (Minn et al., 1997; Muchmore et al., 1996; Schendel et al., 1997), has led to the proposition that these proteins might directly modulate the permeability of the outer mitochondrial membrane to cytochrome c (see below). Furthermore, the release of cytochrome c, i.e. the alteration of the membrane integrity, results in fact from a destructive input which corresponds to a downstream event of the activation phase of PCD. Although apoptosis can occur in the absence of detectable cytochrome c release (Chauhan et al., 1997), efflux of cytochrome c from mitochondria appears to be a critical coordinating step in the killing program towards which converge the multiple signaling pathways and beyond which are initiated the entire panel of apoptotic features, procaspase 3 expressing cells being then irreversibly committed to die (Li et al., 1997). With 
this perspective, the possible mechanisms involved in activation of this central control may be envisaged from data concerning mediators of the death signal transduction cascades. For instance, activation of an ICE-like caspase constitutes an early step in Fas and TNF- $\alpha$ receptor signaling (Nagata, 1997) and inhibition of this protease prevents both the release of cytochrome $\mathrm{c}$ from mitochondria and the execution of the Fas-mediated cell death program (Krippner et al., 1996). However, on the one hand, a direct action of caspase on some crucial mitochondrial membrane component has not been determined and, on the other hand, this model does not prevail in all systems as, in numerous PCD, caspase inhibitors have no effect on the loss of cytochrome c (Kluck et al., 1997a; Kluck et al., 1997b). Conversely, the fact that intracellular redox potential could constitute a common central sensor in PCD activation offers an alternative attractive model. In this case, the release of cytochrome $\mathrm{c}$ would be the result of an activating oxidative imbalance, an upstream event of the transduction cascade leading to the alteration of some redox sensitive crucial regulatory elements of the outer mitochondrial membrane permeability, e.g. by a shift of the redox state of some sulfhydryl groups to a more inactivating oxidized state. 
The cytochrome c signaling is distinct from that of AIF

Although the mechanism(s) by which cytochrome $\mathrm{c}$ is released from mitochondria remains to be determined, some observations suggest that the cytochrome c-mediated PCD is probably distinct from the above described AIF-mediated one (Susin et al., 1997). First, while AIF release occurs after the PT-associated mitochondrial depolarization, some authors reported that cytochrome $\mathrm{c}$ become extractible from mitochondria befores the drop of $\Delta \Psi_{\mathrm{m}}$ occur (Adachi et al., 1997; Kluck et al., 1997a; Kluck et al., 1997b; Krippner et al., 1996; Yang et al., 1997). However, it must be kept in mind that a disruption of the $\Delta \Psi_{\mathrm{m}}$ occuring in a subpopulation of mitochondria would not be detected by the method used. Furthermore, it has been shown that induction of PT can cause cytochromec release (Ellerby et al., 1997; Kantrow and Piantadosi, 1997). Second, cytosolic cytochrome c participates in activating a DEVD sensitive caspase, probably the caspase-3 (originally named CPP32), whereas AIF directly induces nuclear apoptosis. Finally, cytochrome c requires additional cytosolic factors to promote apoptotic changes and is not an obligatory mediator of PCD (Chauhan et al., 1997; Li et al., 1997). On the other hand, AIF, once released from mitochondria, functions without cytosol and is insensitive to DEVD. Beyond their differences, these two "execution caspase" activating 
pathways illustrate the sophistication and the apparent molecular redundancy which characterize the mammalian cell death. They may correspond to alternative and independent links between death-triggering stimuli and the execution machinery or, in contrast, they may work together to induce complete PCD.

\section{Proteins of the Bcl-2 family counteract mitochondria derived pro-apoptotic signals}

Bcl-2 related proteins act at several levels, including mitochondria, to prevent cell death

Bcl-2, and other Bcl-2 related proteins like Bcl- $\mathrm{x}_{\mathrm{L}}$ and $\mathrm{Ced}-9$, are negative regulators of cell death, able to prevent cells from undergoing apoptosis induced by various stimuli in a wide variety of cell types (Korsmeyer, 1992; Zhong et al., 1993). However, the mechanism(s) by which proteins of the Bcl-2 family modulate apoptosis is not yet well known and several conflicting theories have been proposed. A widely accepted model postulates that homodimers of Bax promote apoptosis, and that the functional effect of Bcl-2 related proteins is to form competing heterodimers with Bax that cannot promote apoptosis (Oltvai et al., 1993; Sedlak et al., 1995). However, in some systems, Bax binding by Bcl-2 was not sufficient to prevent apoptosis and the 
overexpression of $\mathrm{Bcl}-2$ or $\mathrm{Bcl}-\mathrm{x}_{\mathrm{L}}$ can repress apoptosis in the absence of Bax (Cheng et al., 1996; Knudson and Korsmeyer, 1997). Thus, while an in vivo competition exists between Bax and Bcl-2, each is able to regulate apoptosis independently.

Bcl-2 (Akao et al., 1994; Chen et al., 1989; de Jong et al., 1994; Hockenbery et al., 1990; Janiak et al., 1994; Krajewski et al., 1993; Nakai et al., 1993; Nguyen et al., 1993), Bcl-x (Gonzalez-Garcia et al., 1994), Mcl-1 (Wang and Studzinski, 1997; Yang et al., 1995), the BHRF1 Epstein-Barr virus protein (Hickish et al., 1994) and probably other members of the Bcl-2 family are localized to the cytoplasmic surfaces of the nuclear envelope, the endoplasmic reticulum and the outer mitochondrial membrane. This membrane association is of functional significance as mutant Bcl-2 molecules lacking this membrane anchorage capacity are less effective at preventing apoptosis in some systems (Borner et al., 1994; Nguyen et al., 1994; Zhu et al., 1996).

$B c l-2$ can block apoptosis of cells devoid of mitochondrial DNA ( $\rho^{0}$ cells) (Jacobson et al., 1993). This result show that, in these cells that do not have a functional respiratory chain but nevertheless maintain a $\Delta \Psi_{\mathrm{m}}$ close to the normal (Marchetti et al., 1996; Sidoti-de Fraisse et al., 1997; Skowronek et al., 1992), the anti-apoptotic activity of $b c l-2$ can always be exerted. Thus, the anti-apoptotic effect of $b c l-2$ is linked to activities that are still present in mitochondria of $\rho^{0}$ cells or is exerted at several levels in 
the cell. Indeed, recent studies (Borner et al., 1994; Nguyen et al., 1994; Zhu et al., 1996) have reported that, in inhibiting apoptosis in MDCK cells, a mutant Bcl-2 molecule whose anchorage is targeted specifically to the mitochondria is as effective as the wild type protein, whereas mutant Bcl-2 targeted to the ER loses this capacity. In contrast, Bcl-2 targeted to the ER in the Rat-1/myc fibroblasts proved to be more active than when targeted to mitochondria. Thus, Bcl-2 mutants with restricted subcellular location reveal distinct pathways for apoptosis depending on cell type. When associated to the endoplasmic reticulum membrane, Bcl-2 could be involved in maintenance of the calcium homeostasis (Distelhorst et al., 1996; He et al., 1997; Lam et al., 1994), while it could modulate protein subcellular trafficking through nuclear pores (Ryan et al., 1994). The next paragraph will present the data showing that mitochondria associated Bcl-2s inhibit apoptosis at least at three levels: control of the redox potential via mitochondrial thiols, regulation of membrane permeability to small pro-apoptotic molecules and anchorage to the mitochondrial membranes of pro-apoptotic proteins (Kroemer, 1997b; Reed, 1997). 
$B c l-2$ and Bcl- $x_{L}$ inhibits apoptosis by providing a protection against ROS and/or shifting the cellular redox potential to a more reduced state

ROS are important physiological reactants in mitochondria (Richter et al., 1995) and several lines of evidence support the idea that Bcl-2 acts in an antioxidant pathway to suppress apoptosis. Yeast mutants lacking superoxide dismutase were partially rescued by expression of Bcl-2 (Kane et al., 1993; Longo et al., 1997). Following an apoptotic signal, overexpression of Bcl-2 suppressed lipid peroxidation completely (Hockenbery et al., 1993). Bcl-2 deficient mice turn gray with the second hair follicle cycle, implicating possibly a defect in redox-regulated melanin synthesis (Veis et al., 1993). Bcl-2 can protect neural cells from delayed death resulting from chemical hypoxia and reenergization, and may do so by an antioxidant mechanism (Myers et al., 1995) (reviewed in (Korsmeyer et al., 1995).

The way by which Bcl-2 protects from ROS remains unclear. In some systems, Bcl-2 appears to influence the generation of oxygen free radicals (Kane et al., 1993) while in other cases it does not affect ROS production but does prevent oxidative damage to cellular constituents (Hockenbery et al., 1993; Tyurina et al., 1997). It has also been 
proposed that it functions as a pro-oxidant and influences the levels of ROS, inducing in this way endogenous cellular antioxidants (Steinman, 1995).

However, apoptosis can proceed normally, and can be prevented by Bcl-2, under anaerobic conditions which minimize the formation of ROS (Jacobson and Raff, 1995; Shimizu et al., 1995). This observation reinforces the view that Bcl-2 acts in more than one way either to prevent the induction of apoptosis by different stimuli (ROS dependent or not) or to control different aspects of the apoptotic effector pathway (reviewed in (Jacobson, 1996). As described above, apoptosis might be modulated by redox sensitive proteins via their sulfhydryl groups and antioxidants such as reduced glutathione or other thiols may modify the functions of these proteins.

Several authors have studied the effect of Bcl-2s on cellular redox potential. Activities of antioxidant enzymes and levels of glutathione and pyridine nucleotides have been measured in pheochromocytoma PC12 and the hypothalamic GnRH cell line GT17 cells transfected with $b c l-2$ (Ellerby et al., 1996). Both cell lines overexpressing $b c l-2$ had elevated total glutathione levels when compared with control transfectants. The ratios of oxidized glutathione to total glutathione in PC12 and GT1-7 cells overexpressing $b c l$ 2 were significantly reduced. In addition, the NAD+/NADH ratio of $b c l$-2-expressing PC12 and GT1-7 cells was two- to threefold less than that of control cell lines while they 
had approximately the same level of catalase, superoxide dismutase, glutathione peroxidase and glutathione reductase activities as control cells. These results indicate that the overexpression of $b c l-2$ shifts the cellular redox potential to a more reduced state, without consistently affecting the major cellular antioxidant enzymes. Furthermore, depleting cellular thiols reversed the resistance to radiation in $\mathrm{Bcl}-2$ expressing lymphoma cell lines (Mirkovic et al., 1997).

The ability of bax and $b c l-x_{L}$ to affect GSH was assessed in interleukin (IL)-3dependent murine prolymphocytic FL5.12 cells (Bojes et al., 1997). Overall levels of GSH increased in $b c l-x_{L}$ transfectants while, in cells overexpressing $b a x$, GSH was reduced by approximately $36 \%$. There were no consistent differences between these cell lines in the activities of superoxide dismutase, catalase, glutathione peroxidase or glutathione reductase. Following IL-3 withdrawal-induced apoptosis, control cells and bax transfectants exhibit a rapid loss of intracellular GSH that seemed to occur due to a translocation out of the cell. Cells overexpressing $b c l-x_{L}$ did not lose significant amounts of GSH upon withdrawal of IL-3, and no apoptosis was evident. These results suggest a possible role for GSH in the mechanism by which Bcl-xL prevents cell death.

Thus, both Bcl-2 and Bcl- $\mathrm{x}_{\mathrm{L}}$ can protect cells from apoptosis by shifting the cellular redox potential to a more reduced state. Assuming that mitochondrial thiols 
constitute a critical sensor of the cellular redox potential during apoptosis (Marchetti et al., 1997), these effects could be at the mitochondrial level.

\section{Bcl-2 inhibits apoptosis by preventing permeability transition}

Nuclei and mitochondria have been purified from hybridomas of $\mathrm{T}$ cells transfected by $b c l-2$ to study how Bcl-2 suppress apoptosis in in vitro experiments (Zamzami et al., 1996b). Treatment with atractyloside has shown that, in contrast to mitochondria purified from control cells, mitochondria purified from cells transfected by bcl-2 do not provoke nuclear apoptosis. On the contrary, nuclei purified from cells transfected by $b c l-2$ show a condensation of the chromatin and a fragmentation of the DNA when they are confronted to control mitochondria treated with atractyloside. Furthermore, $b c l-2$ inhibits the induction of permeability transition by agents such as atractyloside, oxidants and protonophores. These results show that, even if Bcl-2 intervenes also during latter cytoplasmic events (Guénal et al., 1997), at least a part of its inhibitory activity on apoptosis is exerted by acting on the mitochondrial permeability transition (Fig. 1) (Decaudin et al., 1997). Moreover, the structure of a protein of the Bcl-2 family $\left(B c l-x_{L}\right)$ has been established (Muchmore et al., 1996). It recalls that of bacterial toxins, especially the diphtheric toxin, that form a $\mathrm{pH}$-sensitive transmembrane channel. 
Furthermore, the pro-apoptotic Bax protein can form channels (Antonsson et al., 1997), as reported also for the anti-apoptotic proteins Bcl- $\mathrm{x}_{\mathrm{L}}$ (Minn et al., 1997) and Bcl-2 (Schendel et al., 1997). However, the intrinsic properties of Bax and those of Bcl- $\mathrm{x}_{\mathrm{L}}$ and Bcl-2 reveal differences. The chanel forming activity of Bcl- $\mathrm{x}_{\mathrm{L}}$ and $\mathrm{Bcl}-2$ is observed at highly acidic $\mathrm{pH}$ while $\mathrm{Bax}$ form chanel in a wide range of $\mathrm{pH}$ including at $\mathrm{pH}=7$, those found in cells. Furthermore, Bcl-2 can block the pore-forming activity of Bax. These results strengthen the hypothesis that these proteins are constituents of the mitochondrial PT pores. Bax might promote cell death by allowing the efflux of ions and small molecules across the mitochondrial membranes, thus triggering permeability transition, while Bcl-2 might counteract this effect.

Bcl-2 and Bcl- $x_{L}$ inhibits apoptosis by preventing release of cytochrome $c$ from mitochondria

Released of cytochrome c into the cytosol induces nuclear apoptosis (see above). It has been shown that $\mathrm{Bcl}-2$ inhibits release of cytochrome $\mathrm{c}$ from the mitochondria into the cytosol (Kluck et al., 1997a; Yang et al., 1997). Thus, one level of action of Bcl-2 is to control the efflux of cytochrome $\mathrm{c}$ from the mitochondrial intermembrane space through the outer membrane and into the cytosol where caspases are found. It remains to 
be determined whether this efflux is done through Bax containing channels. Postmitochondrial fractions from cells that overexpress Bcl-2 both prevent and reverse cytochrome c inactivation in cell free experiments (Adachi et al., 1997), suggesting that Bcl-2 might even allow to transport cytochrome c back into mitochondria.

Bcl- $\mathrm{x}_{\mathrm{L}}$ inhibits AraC-induced preapoptotic accumulation of cytochrome $\mathrm{c}$ in the cytosol (Kim et al., 1997). Cells that overexpress Bcl-x $x_{L}$ fail to accumulate cytosolic cytochrome $\mathrm{c}$ or to undergo apoptosis in response to genotoxic stress. Co-immunoprecipitation studies have shown that cytochrome $\mathrm{c}$ binds to $\mathrm{Bcl}-\mathrm{x}_{\mathrm{L}}$ and not

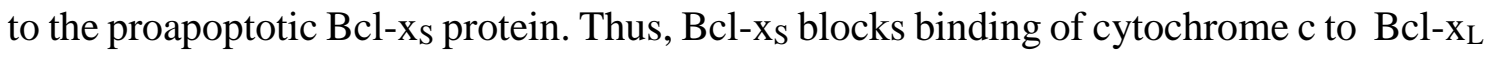
(Kharbanda et al., 1997). These findings support the hypothesis that $\mathrm{Bcl}-\mathrm{x}_{\mathrm{L}}$, as well as Bcl-2, protect cells from apoptosis by inhibiting the availability of cytochrome $\mathrm{c}$ in the cytosol (Fig.1).

Bcl-2 inhibits apoptosis by docking proteins to the mitochondria

Bcl-2 has also been found to interact (at least in two hybrid or co-immunoprecipitation experiments) with several other cellular proteins that do not belong to the Bcl-2 related proteins family. These proteins include Nip1, Nip2, and Nip3, the function of which is unknown (Boyd et al., 1994), the GTPase R-ras p23 (Fernandez 
and Bischoff, 1993), Raf-1 (Ali et al., 1997; Wang et al., 1994), BAG-1 (Takayama et al., 1995), the cellular prion protein (PrP) (Kurschner and Morgan, 1995), the p53 bindingprotein p53-BP2 (Naumovski and Cleary, 1996), the protein phosphatase calcineurin (Shibasaki et al., 1997) and the mitochondrial membrane protein carnitine palmitoyltransferase I (Paumen et al., 1997). At least some of these interactions could reflect the ability of Bcl-2 to relocalize cellular proteins to mitochondrial membranes.

Bcl-2 binds to BAG-1 (Takayama et al., 1995) that can also interact with Raf-1 (Wang et al., 1996b). Active Raf-1 fused with targeting sequences from an outer mitochondrial membrane protein protect cells from apoptosis and phosphorylate BAD, a proapoptotic Bcl-2 homologue (Wang et al., 1996a). Furthermore, plasma membranetargeted Raf-1 did not protect from apoptosis and resulted in phosphorylation of ERK-1 and ERK-2 while Raf-1 improved Bcl-2-mediated resistance to apoptosis. Bcl-2 can therefore target Raf-1 to mitochondrial membranes, allowing this kinase to phosphorylate BAD. However, the link between Raf-1 and the mitochondrial changes occurring during apoptosis are not yet known and bcl-2 does not always require c-raf-1 kinase activity and an associated mitogen-activated protein kinase signaling pathway for its survival function (Olivier et al., 1997). 
Recently, a connection has been made between members of the CED-9/Bcl-2

family and caspases. Mutations that reduce or eliminate CED-9 activity also disrupt its ability to bind CED-4 (Spector et al., 1997). CED-9 (and Bcl- $\mathrm{x}_{\mathrm{L}}$ ) was found to interact with and inhibit the function of CED-4. Furthermore, CED-4 can simultaneously interact with CED-3 (Irmler et al., 1997) (or mammalian caspases (Chinnaiyan et al., 1997b)). Thus, CED-9 might control C. elegans cell death by binding to and regulating CED-4 and CED-3 activities. The CED-9 protein, like the mammalian Bcl-2 related proteins, is localized to intracellular membranes and the perinuclear region, whereas CED-4 was distributed in the cytosol. Expression of CED-9, but not a mutant lacking the carboxyterminal hydrophobic domain, targeted CED-4 from the cytosol to intracellular membranes in mammalian cells (Wu et al., 1997). These results show that CED-9 achieves its anti-apoptotic effect by blocking the ability of CED-4 to promote the activation of CED-3 .

A similar mechanism could also exist in mammalian cells. Although they do not show affinity for each other, Bcl- $\mathrm{x}_{\mathrm{L}}$ associate with caspase-1 when the two proteins are co-expressed in mammalian cells suggesting that a CED-4 could link Bcl- $\mathrm{x}_{\mathrm{L}}$ and caspase-1 (Chinnaiyan et al., 1997a). Bcl- $\mathrm{X}_{\mathrm{L}}$ interacts with and inhibits the function of CED-4 (Chinnaiyan et al., 1997b). Furthermore, the human protease activating factor 
(Apaf-1), which participates in the cytochrome c-dependent activation of caspase-3, contains a caspase-recruitment domain (CARD). Altogether, these results suggest that Apaf-1, like the nematode CED-4, acts by activating caspases and could provide the physical link between Bcl-2 related proteins and caspases. (Zou et al., 1997).

In murine thymocytes, $\mathrm{Bcl}-2$ is exclusively membrane-bound, whereas $\mathrm{Bcl}-\mathrm{x}_{\mathrm{L}}$ is present in both soluble and membrane-bound forms and Bax is present predominantly in the cytosol. Induction of apoptosis by dexamethasone or gamma-irradiation shifts the subcellular locations of Bax and Bcl- $\mathrm{x}_{\mathrm{L}}$ from soluble to membrane-bound forms (Hsu et al., 1997). Inhibition of apoptosis with cycloheximide inhibits the movement of Bax and Bcl- $x_{L}$ from the cytosol into intracellular membranes (Hsu et al., 1997). Similar results were obtained during L929 and Cos-7 apoptosis where Bax was shown to move from cytosol to mitochondria (Wolter et al., 1997). Since Bax and Bik can disrupt the association between CED-9 (or Bcl-xL) and CED-4 (Chinnaiyan et al., 1997b), it is tempting to speculate that $\mathrm{Bcl}-\mathrm{x}_{\mathrm{L}}$ and possibly other members of the Bcl-2 protein family inhibit apoptosis by maintaining the procaspases/Apaf-1 complexes associated to mitochondrial membranes and that Bax and Bik by dissociating the complexes permit the activation of procaspases (Fig. 2). 


\section{Evolutionary origin of the mitochondrial control of apoptosis}

A part of the apoptotic machinery might exist in unicellular eukaryotes

Processes resembling apoptosis have been described in the amoeba Dictyostelium

(Cornillon et al., 1994) and in protozoan trypanosomes (Ameisen et al., 1995b; Welburn

et al., 1996). These observations suggest that at least a part of mechanisms of the programmed cellular death existed before multicellular organisms appeared. Indeed, some elements reminiscent of apoptosis are found in unicellular organisms.

Phenomena similar to permeability transition have been described in yeast (Szabo et al., 1995). However, the analysis of open reading frames found in the sequence of the genome of the yeast Saccharomyces cerevisiae does not reveal a gene coding a protein containing sequences similar to the conserved regions of the Bcl-2 family proteins or caspases (S. Gaumer, unpublished results). Thus, their does not seem to be in yeast a gene coding an equivalent of Bcl-2 or caspases. Nevertheless, the expression of bax in the yeast $S$. cerevisiae is lethal in the presence of a functional respiratory chain and Bcl2 inhibits the yeast cell death induced by Bax when it possesses its membrane anchorage sequence (Greenhalf et al., 1996). Furthermore, mitochondria of Bax- expressing yeast cells release cytochrome $\mathrm{c}$ and this efflux is inhibited by coexpression of $\mathrm{Bcl}-\mathrm{x}_{\mathrm{L}}$ (Manon 
et al., 1997). Bax and Bak (another pro-apoptotic member of the Bcl-2 family) are also capable of provoking the death of the yeast Schizosaccharomyces pombe (Ink et al., 1997; Jürgensmeier et al., 1997; Tao et al., 1997). The expression of ced-4 provokes some morphological modifications of the apoptosis in S. pombe (James et al., 1997) and a CDC48 mutant of $S$. cerevisiae exhibits some nuclear and membrane allmarks of apoptosis in restricitve conditions (Madeo et al., 1997). These observations suggest that some elements involved in the mammalian cell death exist in yeasts.

Did programmed cell death appear after the endosymbiotic event giving rise to mitochondria?

It is now accepted that mitochondria have evolved from bacteria that were endocytosed by the ancestor of eukaryotic cells (Gray, 1989). In the course of evolution, most of genes of this ancestral bacterium would have migrated to the nucleus of the host. However, the limitations to in vivo import of hydrophobic proteins into mitochondria would have constrained the host to preserve a semi-autonomous genome (Claros et al., 1995).

Cytochrome $\mathrm{c}$ and molecules that could constitute the permeability transition pore, such as cyclophilines and porins, exist in prokaryotes (Schulz, 1986). Other constituents 
of this pore, the adenosine nucleotide translocators and the peripheral benzodiazepins receptor, could have homologues in the bacterium Rhodobaxter capsulatus (Armstrong et al., 1989; Carmeli and Lifshitz, 1989). Bcl- $\mathrm{x}_{\mathrm{L}}$ shares some structural features with the colicines of E. coli (Muchmore et al., 1996). Mitochondrially-encoded subunit 8 of ATP synthase has an hydropathy profile similar to those of the hok family of prokaryotic respiratory toxins, some of whose members are involved in plasmid maintenance, through postsegregational killing of cells that lose the plasmid at cell division. Thus, it has been proposed that the subunit 8 of ATP synthase evolved from an hok-like protein, whose original role was the maintenance of an extrachromosomal replicon in the endosymbiont ancestor of mitochondria (Jacobs, 1991). In the same way, it can be hypothesized that the mechanism originally involved in the maintenance of the symbiosis between the bacterial ancestor of the mitochondria and the host cell precursor of eukaryotes, provided the basis for the actual mechanism controlling cell survival (Frade and Michaelidis, 1997; Kroemer, 1997a). This hypothesis supposes that some proteins, situated at the endosymbiont/host interface, would have played a strategic role to allow the establishment of the endosymbiosis giving rise to mitochondria, but would have also provided the basis to a control of nuclear programmed death. Metazoans would have exploited this possibility by connecting the mitochondrial effectors of cell death to the 
pathways of signal transduction (figure 3). This hypothesis is in agreement with the capacity of cells devoid of mitochondrial DNA to undergo apoptosis. All the mitochondrial proteins involved in apoptosis or its control (Bcl-2 related proteins, adenosine nucleotide translocators, peripheral benzodiazepins receptor, porin, cytochrome c, AIF... ) are nuclearly-encoded and are present in the mitochondria of cells devoid of mitochondrial DNA. Furthermore, in nematodes ced-9 is transcribed in the form of a polycistronic mRNA also containing the gene encoding the cytochrome b560, a component of the complex II of the respiratory chain (Hengartner and Horvitz, 1994). This observation suggests that $c e d-9$ and $c y t-1$ have been co-transferred from the genome of the ancestor of the mitochondria to the nucleus and therefore that ced-9, and members of the $b c l-2$ gene family, have evolved from the genome of the endosymbiont.

\section{Conclusions and perspectives}

In conclusion, multiple reports from the literature point to the mitochondrion as constituting a pivot component of the cell death machinery. At a first level, mitochondria can contribute to PCD signaling, as shown in TNF- $\alpha$ - or ceramide-induced cell death during which increased mitochondrial ROS production appears as an early event of the induction phase. At a second level, mitochondria are involved in the control of the 
activation of the cell death machinery by docking at their surface, via Bcl-2s, execution caspases or by sequestering, in the intermembrane space, caspase activators as AIF or cytochrome c. These observations strengthen a model in which the endosymbiotic event giving rise to mitochondria provided the basis for the mitochondrial localization of killer components and ultimately for the control of nuclear programmed death.

This recent accumulation of data has also generated a number of new questions. Future works must address the connection between cell death signals and mitochondrial alterations. The study of Bad regulation, a proapoptotic Bcl-2 member which is supposed to counteract Bcl-2 has provided an example of how survival factors counteract PCD. Indeed, Bad is inactivated by phosphorylation by Akt (Datta et al., 1997; del Peso et al., 1997) and Raf-1 (Wang et al., 1996a), two kinases involved in survival signals transduction. It has been suggested that, in the absence of phosphorylation, Bad induces cell death possibly via the formation of heterodimers with Bcl- $\mathrm{x}_{\mathrm{L}}$ (or Bcl-2 depending of the cell type) and the concomitant generation of Bax homodimers. Assuming that all mammalian cells constitutively express all the protein components required to execute the death program (Jacobson et al., 1994), these results suggest that Bax (or an other similar pro-apoptotic member of the Bcl-2 family) are ubiquitously expressed and that survival requires their continuous inhibition. Taking into account the mitochondrial 
membrane localization of these proteins and their pore forming properties, it can be proposed that this kind of regulation operates at the mitochondrial level to control PT pores opening and efflux of AIF and cytochrome c. The situation is clearly different in the case of apoptosis induced by CD95-like surface receptors causing direct activation of upstream caspases during the initiation phase of the process. In this case, one might hypothesize that these caspases cleave some specific mitochondrial components (a Bcl-2 family member?) leading to PT and more generally to disruption of the mitochondrial integrity. Identification of the targets of these caspases could provide clues for the understanding of the mechanism leading to apoptosis associated mitochondrial changes.

The mechanism allowing for the release of AIF and cytochrome c needs further investigations. Opening of PT pores, which are thought to connect the mitochondrial matrix to the cytosol, within the contact sites between inner and outer mitochondrial membranes (Beutner et al., 1996) and is only permeable to small compounds (molecular mass $<1500 \mathrm{Da}$ ) and thus is probably not the structure directly responsible for the efflux of these intermembrane space apoptogenic proteins. Future works will have to determine the way used by AIF and cytochrome $\mathrm{c}$ to leave the mitochondria. . Opening of the PT pore could be just a first step of a cascade of events causing an increase in the permeability of the outer mitochondrial membrane. At present, it remains elusive whether this 
permeability increase is due to the action of specific pores in the outer membrane and/or to its mechanic disruption secondary to an increase in matrix volume.

Another exciting question to resolve is the occurence of an apoptosis-like phenotype associated with a specific mutation in S. cerevisiae (Madeo et al., 1997). This yeast species seems do not contain caspases or Bcl-2s gene and its cytochrome $\mathrm{c}$ has been shown to be ineffective to induce nuclear apoptosis in acellular assay (Kluck et al., 1997b). These data suggest the existence of yet unknown PCD pathways in which the place and the role of mitochondria remain to be determined. 


\section{ACKNOWLEDGEMENTS}

We thank Dr Spencer Brown, Sébastien Gaumer and Vincent Rincheval for their critical reading of the manuscript. 


\section{References}

Adachi, S., Cross, A. R., Babior, B. M. \& Gottlieb, R. A. (1997) Bcl-2 and the outer mitochondrial membrane in the inactivation of cytochrome c during Fas-mediated apoptosis, J. Biol. Chem. 272, 21878-21882.

Akao, Y., Otsuki, Y., Kataoka, S., Ito, Y. \& Tsujimoto, Y. (1994) Multiple subcellular localization of $\mathrm{Bcl}-2$ : detection in nuclear outer membrane, endoplasmic reticulum membrane, and mitochondrial membranes, Cancer Res. 54, 2468-2471.

Ali, S. T., Coggins, J. R. \& H.T., J. (1997) The study of cell death proteins in the outer mitochondrial membrane chemical cross-linking, Biochem. J. 325, 321-324.

Ameisen, J. C., Estaquier, J., Idziorek, T. \& De Bels, F. (1995a) The relevance of apoptosis to AIDS pathogenesis, Trends Cell Biol. 5, 27-32.

Ameisen, J. C., Idziorek, T., Billaut-Mulot, O., Loyens, M., Tissier, J. P., Potentier, A. \& Ouaissi, A. (1995b) Apoptosis in unicellular eukaryote (Trypanosoma cruzi): implications for the evolutionary origin and role of programmed cell death in the control of cell proliferation, differentiation and survival, Cell Death Differ. 2, 285-300. 
Antonsson, B., Conti, F., Ciavatta, A., Montessuit, S., Lewis, S., Martinou, I., Bernasconi, L., Bernard, A., Mermod, J. J., Mazzei, G., Maundrell, K., Gambale, F., Sadoul, R. \& Martinou, J. C. (1997) Inhibition of Bax Channel-Forming Activity by Bcl-2, Science 277, 370-372.

Armstrong, G. A., Alberti, M., Leach, F. \& Hearst, J. E. (1989) Nucleotide sequence, organization and nature of the protein product of the carotenoid biosynthesis gene cluster of Rhodobaxter capsulatus, Mol. Gen. Genet. 216, 254-268.

Bernardi, P., Vassanelli, S., Veronese, P., Colonna, R., Szabo, I. \& Zoratti, M. (1992) Modulation of the mitochondrial permeability transition pore. Effect of protons and divalent cations, J. Biol. Chem. 267, 2934-2939.

Beutner, G., Ruck, A., Riede, B., Welte, W. \& Brdiczka, D. (1996) Complexes between kinases, mitochondrial porin and adenylate translocator in rat brain resemble the permeability transition pore, FEBS Lett. 396, 189-195.

Bojes, H. K., Datta, K., Xu, J., Chin, A., Simonian, P., Nunez, G. \& Kehrer, J. P. (1997) ${ }^{B c l-x_{L}}$ overexpression attenuates glutathione depletion in FL5.12 cells following interleukin-3 withdrawal, Biochem. J. 315-319. 
Borner, C., Martinou, I., Mattmann, C., Irmler, M., Schaerer, E., Martinou, J. C. \& Tschopp, J. (1994) The protein bcl-2 alpha does not require membrane attachment, but two conserved domains to suppress apoptosis, J. Cell Biol. 126, 1059-1068.

Boyd, J. M., Malstrom, S., Subramanian, T., Venkatesh, L. K., Schaeper, U., Elangovan, B., D'Sa, E. C. \& Chinnadurai, G. (1994) Adenovirus E1B 19 kDa and Bcl-2 proteins interact with a common set of cellular proteins, Cell 79, 341-351.

Bursch, W., Oberhammer, F. \& Schulte-Hermann, R. (1992) Cell death by apoptosis and its protective role against disease, Trends Pharmacol. Sci. 13, 245-251.

Carayon, P., Portier, M., Dussossoy, D., Bord, A., Petitpretre, G., Canat, X., Le Fur, G. \& Casellas, P. (1996) Involvement of peripheral benzodiazepine receptors in the protection of hematopoietic cells against oxygen radical damage, Blood 87, 3170-3178.

Carmeli, C. \& Lifshitz, Y. (1989) Nucleotide transport in Rhodobaxter capsulatus, J. Bacteriol. 171, 6521-6525.

Chauhan, D., Pandey, P., Ogata, A., Teoh, G., Krett, N., Halgren, R., Rosen, S., Kufe, D., Kharbanda, S. \& Anderson, K. (1997) Cytochrome c-dependent and -independent induction of apoptosis in multiple myeloma cells, J. Biol. Chem. 272, 29995-29997. 
Chen, L. Z., Nourse, J. \& Cleary, M. L. (1989) The bcl-2 candidate proto-oncogene product is a 24-kilodalton integral-membrane protein highly expressed in lymphoid cell lines and lymphomas carrying the $\mathrm{t}(14 ; 18)$ translocation, Mol. Cell. Biol. 9, 701-710.

Cheng, E. H., Levine, B., Boise, L. H., Thompson, C. B. \& Hardwick, J. M. (1996) Baxindependent inhibition of apoptosis by Bcl-x ${ }_{\mathrm{L}}$, Nature 379, 554-556.

Chinnaiyan, A. M., Chaudhary, D., O'Rourke, K., Koonin, E. V. \& Dixit, V. M. (1997a) Role of CED-4 in the activation of CED-3, Nature 388, 728-729.

Chinnaiyan, A. M., O'Rourke, K., Lane, B. R. \& Dixit, V. M. (1997b) Interaction of CED4 with CED-3 and CED-9: a molecular framework for cell death, Science 275, 1122-1126.

Clarke, P. G. H. (1990) Developmental cell death: morphological diversity and multiple mechanisms, Anat. Embryol. 181, 195-213.

Clarke, P. G. H. \& Clarke, S. (1996) Nineteenth century research on naturally occuring cell death and related phenomena, Anat. Emryol. 193, 81-99.

Claros, M. G., Perea, J., Shu, Y., Samatey, F. A., Popot, J. L. \& Jacq, C. (1995) Limitations to in vivo import of hydrophobic proteins into yeast mitochondria. The case of a cytoplasmically synthesized apocytochrome b., Eur. J. Biochem. 228, 762-771. 
Cornillon, S., Foa, C., Davoust, J., Buonavista, N., Gross, J. D. \& Golstein, P. (1994) Programmed cell death in Dictyostelium, J. Cell Sci. 107, 2691-2704.

Datta, S. R., Dudek, H., Tao, X., Masters, S., Fu, H., Gotoh, Y. \& Greenberg, M. E. (1997) Akt phosphorylation of BAD couples survival signals to the cell- intrinsic death machinery, Cell 91, 231-241.

de Jong, D., Prins, F. A., Mason, D. Y., Reed, J. C., van Ommen, G. B. \& Kluin, P. M. (1994) Subcellular localization of the bcl-2 protein in malignant and normal lymphoid cells, Cancer Res 54, 256-260.

Decaudin, D., Geley, S., Hirsch, T., Castedo, M., Marchetti, P., Macho, A., Kofler, R. \& Kroemer, G. (1997) $\mathrm{Bcl}-2$ and $\mathrm{Bcl}-\mathrm{X}_{\mathrm{L}}$ antagonize the mitochondrial dysfunction preceding nuclear apoptosis induced by chemotherapeutic agents, Cancer Res. 57, 62-67. del Peso, L., Gonzalez Garcia, M., Page, C., Herrera, R. \& Nunez, G. (1997) Interleukin3-induced phosphorylation of BAD through the protein kinase Akt, Science 278, 687689.

Distelhorst, C. W., Lam, M. \& McCormick, T. S. (1996) Bcl-2 inhibits hydrogen peroxide-induced ER Ca2+ pool depletion, Oncogene 12, 2051-2055. 
Duan, H., Chinnaiyan, A. M., Hudson, P. L., Wing, J. P., He, W. W. \& Dixit, V. M. (1996) ICE-LAP3, a novel mammalian homologue of the Caenorhabditis elegans cell death protein Ced-3 is activated during Fas- and tumor necrosis factor-induced apoptosis, $271,1621-1625$.

Ellerby, H. M., Martin, S. J., Ellerby, L. M., Naiem, S. S., Rabizadeh, S., Salvesen, G. S., Casiano, C. A., Cashman, N. R., Green, D. R. \& Bredesen, D. E. (1997) Establishment of a cell-free system of neuronal apoptosis: comparison of premitochondrial, mitochondrial, and postmitochondrial phases, J. Neurosci. 17, 6165-6178.

Ellerby, L. M., Ellerby, H. M., Park, S. M., Holleran, A. L., Murphy, A. N., Fiskum, G., Kane, D. J., Testa, M. P., Kayalar, C. \& Bredesen, D. E. (1996) Shift of the cellular oxidation-reduction potential in neural cells expressing Bcl-2, J. Neurochem. 67, 12591267.

Ellis, H. M. \& Horvitz, H. R. (1986) Genetic control of programmed cell death in the nematode C. elegans, Cell 44, 817-829.

Ellis, R. E., Yuan, J. Y. \& Horvitz, H. R. (1991) Mechanisms and functions of cell death, Annu. Rev. Cell Biol. 7, 663-698. 
Fernandez, S. M. \& Bischoff, J. R. (1993) Bcl-2 associates with the ras-related protein Rras p23, Nature 366, 274-275.

Frade, J. M. \& Michaelidis, T. M. (1997) Origin of eukaryotic programmed cell death: a consequence of aerobic metabolism?, Bioessays 19, 827-832.

Fraser, A. \& Evan, G. (1996) A License to Kill, Cell 85, 781-781.

Fridovich, I. (1978) The biology of oxygen radicals, Science 201, 875-880.

Golstein, P. (1989) Morts cellulaires et système immunitaire, médecine/sciences 5, 546553.

Golstein, P. (1997) Controlling Cell Death, Science 275, 1081-1082.

Gonzalez-Garcia, M., Perez-Ballestero, R., Ding, L., Duan, L., Boise, L. H., Thompson, C. B. \& Nunez, G. (1994) bcl- $\mathrm{X}_{\mathrm{L}}$ is the major $b c l-x$ mRNA form expressed during murine development and its product localizes to mitochondria, Development 120, 3033-3042.

Goossens, V., Grooten, J., De, V. K. \& Fiers, W. (1995) Direct evidence for tumor necrosis factor-induced mitochondrial reactive oxygen intermediates and their involvement in cytotoxicity, Proc. Natl. Acad. Sci. USA 92, 8115-8119. 
Gray, M. W. (1989) The evolutionary origins of organelles., Trends Genet. 5, 294-299.

Greenhalf, W., Stephan, C. \& Chaudhuri, B. (1996) Role of mitochondria and C-terminal membrane anchor Bcl2 in Bax induced growth arrest and mortality in Saccharomyces cerevisiae, FEBS lett. 380, 169-175.

Greenlund, L. J. S., Deckwerth, T. L. \& Johnson Jr, E. M. (1995) Superoxide dismutase delays neuronal apoptosis: a role for reactive oxygen species in programmed neuronal death, Neuron 14, 303-315.

Gudz, T. I., Tserng, K. Y. \& Hoppel, C. L. (1997) Direct inhibition of mitochondrial respiratory cahin complex III by cell-permeable ceramide, J. Biol. Chem. 272, 2415424158.

Guénal, I., Sidoti-de Fraisse, C., Gaumer, S. \& Mignotte, B. (1997) Bcl-2 and Hsp27 act at different levels to suppress programmed cell death, Oncogene 15, 347-360.

Halliwell, B. \& Gutteridge, J. M. (1990) Role of free radicals and catalytic metal ions in human disease: an overview, Methods Enzymol. 1-85.

Halliwell, B. \& Gutteridge, J. M. C. (1989) Free radicals in Biology and Medecine, 
Hartley, A., Stone, J. M., Heron, C., Cooper, J. M. \& Schapira, A. H. (1994) Complex I inhibitors induce dose-dependent apoptosis in PC12 cells: relevance to Parkinson's disease, J. Neurochem. 63, 1987-1990.

He, H., Lam, M., McCormick, T. S. \& Distelhorst, C. W. (1997) Maintenance of Calcium Homeostasis in the Endoplasmic Reticulum by Bcl-2, J. Cell. Biol. 138, 1219-1228.

Hengartner, M. O. (1997) Apoptosis. CED-4 is a stranger no more, Nature 388, 714-715.

Hengartner, M. O. \& Horvitz, H. R. (1994) C. elegans cell survival gene ced-9 encodes a functional homolog of the mammalian proto-oncogene $b c l-2$, Cell 76, 665-676.

Hickish, T., Robertson, D., Clarke, P., Hill, M., di Stefano, F., Clarke, C. \& Cunningham, D. (1994) Ultrastructural localization of BHRF1: an Epstein-Barr virus gene product which has homology with bcl-2, Cancer Res. 54, 2808-2811.

Higuchi, M., Aggarwal, B. B. \& Yeh, E. T. (1997) Activation of CPP32-like protease in tumor necrosis factor-induced apoptosis is dependent on mitochondrial function, J. Clin. Invest. 99, 1751-1758. 
Hockenbery, D., Nunez, G., Milliman, C., Schreiber, R. D. \& Korsmeyer, S. J. (1990)

Bcl-2 is an inner mitochondrial protein that blocks programmed cell death., Nature 348, 334-336.

Hockenbery, D. M., Oltvai, Z. N., Yin, X. M., Milliman, C. L. \& Korsmeyer, S. J. (1993) Bcl-2 functions in an antioxidant pathway to prevent apoptosis, Cell 75, 241-251.

Hofmann, K., Bucher, P. \& Tschopp, J. (1997) The CARD domain: a new apoptotic signalling motif, Trensd Biochem. Sci. 22, 155-156.

Horvitz, H. \& Ellis, S., P. (1982) Programmed cell death in nematode development, Neurosc. Comment. 1, 56-65.

Hsu, Y. T., Wolter, K. G. \& Youle, R. J. (1997) Cytosol-to-membrane redistribution of Bax and Bcl-X(L) during apoptosis, Proc. Natl. Acad. Sci. USA 94, 3668-3672.

Ichas, F., Jouaville, L. S. \& Mazat, J. P. (1997) Mitochondria are excitable organelles capable of generating and conveying electrical and calcium signals, Cell 89, 1145-1153.

Ink, B., Zornig, M., Baum, B., Hajibagheri, N., James, C., Chittenden, T. \& Evan, G. (1997) Human Bak induces cell death in Schizosaccharomyces pombe with 
morphological changes similar to those with apoptosis in mammalian cells, Mol. Cell. Biol. 17, 2468-2474.

Irmler, M., Hofmann, K., Vaux, D. \& Tschopp, J. (1997) Direct physical interaction between the Caenorhabditis elegans 'death proteins' CED-3 and CED-4, FEBS Lett. 406, 189-190.

Ishizaki, Y., Cheng, L., Mudge, A. W. \& Raff, M. C. (1995) Programmed cell death by default in embryonic cells, fibroblasts, and cancer cells, Mol. Biol. Cell. 6, 1443-1458.

Jacobs, H. T. (1991) Structural similarities between a mitochondrially encoded polypeptide and a family of prokaryotic respiratory toxins involved in plasmid maintenance suggest a novel mechanism for the evolutionary maintenance of mitochondrial DNA, J. Mol. Evol. 32, 333-339.

Jacobson, M. D. (1996) Reactive oxygen species and programmed cell death, Trends Biochem. Sci. 21, 83-86.

Jacobson, M. D., Burne, J. F., King, M. P., Miyashita, T., Reed, J. C. \& Raff, M. C. (1993)

Bcl-2 blocks apoptosis in cells lacking mitochondrial DNA, Nature 361, 365-369. 
Jacobson, M. D., Burne, J. F. \& Raff, M. C. (1994) Programmed Cell Death and Bcl-2 Protection in the Absence of a Nucleus, EMBO J. 13, 1899-1910.

Jacobson, M. D. \& Raff, M. C. (1995) Programmed cell death and Bcl-2 protection in very low oxygen, Nature $374,814-816$.

James, C., Gschmeissner, S., Fraser, A. \& Evan, G. I. (1997) CED-4 induces chromatin condensation in Schizosaccharomyces pombe and is inhibited by direct physical association with CED-9, Curr. Biol. 7, 246-252.

Janiak, F., Leber, B. \& Andrews, D. W. (1994) Assembly of Bcl-2 into microsomal and outer mitochondrial membranes, J. Biol. Chem. 269, 9842-9849.

Jürgensmeier, J., Krajewski, S., Armstrong, R. C., Wilson, G. M., Olterdorf, T., Fritz, L. C., Reed, J. C. \& Ottilie, S. (1997) Bax-and Bak-induced cell death in the fission yeast Schizosaccharomyces pombe, Mol. Biol. Cell 8, 325-339.

Kane, D. J., Sarafian, T. A., Anton, R., Hahn, H., Gralla, E. B., Valentine, J. S., Ord, T. \& Bredesen, D. E. (1993) Bcl-2 inhibition of neural death - decreased generation of reactive oxygen species, Science 262, 1274-1277. 
Kantrow, S. P. \& Piantadosi, C. A. (1997) Release of cytochrome c from liver mitochondria during permeability transition, Biochem. Biophys. Res. Commun. 232, 669671.

Kerr, J. F. R. \& Harmon, B. V. (1991) Definition and incidence of apoptosis: an historical perspective, Apoptosis: the molecular basis of cell death, pp. 5-29.

Kerr, J. F. R., Wyllie, A. H. \& Currie, A. R. (1972) Apoptosis: a basic biological phenomenon with wide-ranging implications in tissue kinetics, Br. J. Cancer 26, 239257.

Kharbanda, S., Pandey, P., Schofield, L., Israels, S., Roncinske, R., Yoshida, K., Bharti, A., Yuan, Z. M., Saxena, S., Weichselbaum, R., Nalin, C. \& Kufe, D. (1997) Role for bcl- $\mathrm{X}_{\mathrm{L}}$ as an inhibitor of cytosolic cytochrome $\mathrm{C}$ accumulation in DNA damage-induced apoptosis, Proc. Natl. Acad. Sci. USA 94, 6939-6942.

Kim, C. N., Wang, X., Huang, Y., Ibrado, A. M., Liu, L., Fang, G. \& Bhalla, K. (1997) Overexpression of $\mathrm{Bcl}-\mathrm{X}(\mathrm{L})$ inhibits Ara-C-induced mitochondrial loss of cytochrome $\mathrm{c}$ and other perturbations that activate the molecular cascade of apoptosis, Cancer Res. 57, 3115-3120. 
Kluck, R. M., Bossy-Wetzel, E., Green, D. R. \& Newmeyer, D. D. (1997a) The release of cytochrome c from mitochondria: a primary site for Bcl-2 regulation of apoptosis, Science 275, 1132-1136.

Kluck, R. M., Martin, S. J., Hoffman, B., Zhou, J. S., Green, D. R. \& Newmeyer, D. D. (1997b) Cytochrome c activation of CPP32-like proteolysis plays a critical role in a Xenopus cell-free apoptosis system, EMBO J. 16, 4639-4649.

Knudson, C. M. \& Korsmeyer, S. J. (1997) Bcl-2 and Bax function independently to regulate cell death, Nat. Genet. 16, 358-363.

Korsmeyer, S. J. (1992) Bcl-2 initiates a new category of oncogenes: regulators of cell death, Blood 80, 879-886.

Korsmeyer, S. J. (1995) Regulators of cell death, Trends Genet. 11, 101-105.

Korsmeyer, S. J., Yin, X. M., Oltvai, Z. N., Veis, N. D. \& Linette, G. P. (1995) Reactive oxygen species and the regulation of cell death by the Bcl-2 gene family, Biochim. Biophys. Acta 1271, 63-66.

Krajewski, S., Tanaka, S., Takayama, S., Schibler, M. J., Fenton, W. \& Reed, J. C. (1993) Investigation of the subcellular distribution of the bcl-2 oncoprotein: residence in the 
nuclear envelope, endoplasmic reticulum, and outer mitochondrial membranes, Cancer Res. 53, 4701-4714.

Krippner, A., Matsuno-Yagi, A., Gootlieb, R. A. \& Babior, B. M. (1996) Loss of Function of Cytochrome c in Jurkat Cells Undergoing Fas-mediated Apoptosis, J. Biol. Chem. 271, 21629-21636.

Kroemer, G. (1997a) Mitochondrial implication in apoptosis. Towards an endosymbiont hypothesis of apoptosis evolution, Cell Death Differ. 4, 443-456.

Kroemer, G. (1997b) The proto-oncogene Bcl-2 and its role in regulating apoptosis, Nature Med. 3, 614-620.

Kroemer, G., Petit, P. X., Zamzami, N., Vayssière, J. L. \& Mignotte, B. (1995) The biochemistry of programmed cell death, FASEB J. 9, 1277-1287.

Kroemer, G., Zamzami, N. \& Susin, S. A. (1997) Mitochondrial control of apoptosis, Immunol. Today 18, 44-51.

Kurschner, C. \& Morgan, J. I. (1995) The cellular prion protein (PrP) selectively binds to Bcl-2 in the yeast two-hybrid system, Mol. Brain Res 30, 165-168. 
Lam, M., Dubyak, G., Chen, L., Nunez, G., Miesfeld, R. L. \& Distelhorst, C. W. (1994)

Evidence that BCL-2 represses apoptosis by regulating endoplasmic reticulum-associated Ca2+ fluxes, Proc. Natl. Acad. Sci. USA 91, 6569-6573.

Lancaster, J. R., Laster, S. M. \& Gooding, L. R. (1989) Inhibition of target cell mitochondrial electron transfer by tumor necrosis factor, FEBS Lett. 248, 169-174.

Lennon, S. V., Martin, S. J. \& Cotter, T. G. (1991) Dose-dependent induction of apoptosis in human tumour cell lines by widely diverging stimuli, Cell Prolif. 24, 203-214.

Li, F., Srinivasan, A., Wang, Y., Armstrong, R. C., Tomaselli, K. J. \& Fritz, L. C. (1997) Cell-specific Induction of Apoptosis by Microinjection of Cytochrome c. Bcl-xl has activity independent of cytochrome c release, J. Biol. Chem. 272, 30299-30305.

Liu, X., Kim, C. N., Yang, J., Jemmerson, R. \& Wang, X. (1996) Induction of apoptotic program in cell-free extracts: requirement for dATP and cytochrome c, Cell 86, 147-157.

Longo, V. D., Ellerby, L. M., Bredesen, D. E., Valentine, J. S. \& Gralla, E. B. (1997) Human Bcl-2 reverses survival defects in yeast lacking superoxide dismutase and delays death of wild-type yeast, J. Cell Biol. 137, 1581-1588. 
Macho, A., Castedo, M., Marchetti, P., Aguilar, J. J., Decaudin, D., Zamzami, N., Girard, P. M., Uriel, J. \& Kroemer, G. (1995) Mitochondrial dysfunctions in circulating T lymphocytes from human immunodeficiency virus-1 carriers, Blood 86, 2481-2487.

Macho, A., Hirsch, T., Marzo, I., Marchetti, P., Dallaporta, B., Susin, S. A., Zamzami, N. \& Kroemer, G. (1997) Glutathione depletion is an early and calcium elevation is a late event of thymocyte apoptosis, J. Immunol. 158, 4612-4619.

Madeo, F., Frohlich, E. \& Frohlich, K. U. (1997) A yeast mutant showing diagnostic markers of early and late apoptosis, J. Cell Biol. 139, 729-734.

Manon, S., Chaudhuri, B. \& Guerin, M. (1997) Release of cytochrome c and decrease of cytochrome c oxidase in Bax- expressing yeast cells, and prevention of these effects by coexpression of Bcl-xL, FEBS Lett. 415, 29-32.

Marchetti, P., Decaudin, D., Macho, A., Zamzami, N., Hirsch, T., Susin, S. A. \& Kroemer, G. (1997) Redox regulation of apoptosis: impact of thiol oxidation status on mitochondrial function, Eur. J. Immunol. 27, 289-296. 
Marchetti, P., Susin, S. S., Decaudin, D., Gamen, S., Castedo, M., Hirsch, T., Zamzami, N., Naval, J., Senik, A. \& Kroemer, G. (1996) Apoptosis-associated derangement of mitochondrial function in cells lacking mitochondrial DNA, Cancer Res. 56, 2033-2038.

Martin, S. J. \& Cotter, T. G. (1991) Ultraviolet B irradiation of human leukaemia HL-60 cells in vitro induces apoptosis, Int. J. Radiat. Biol. 59, 1001.

Martinou, J. C. (1993) Bcl-2 and neuronal cell death, Biomed. Pharmacother. 47, 173.

Mayer, A., Neupert, W. \& Lill, R. (1995) Translocation of Apocytochrome c accross the Outer membrane of Mitochondria, J. Biol. Chem. 270, 12390-12397.

Mayer, M. \& Noble, M. (1994) N-acetyl-L-cysteine is a pluripotent protector against cell death and enhancer of trophic factor-mediated cell survival in vitro, Proc. Nathl. Acad. Sci. USA 91, 7496-7500.

McCarthy, N. J., Whyte, M. K. B., Gilbert, C. S. \& Evan, G. I. (1997) Inhibition of Ced3/ICE-related Proteases Does Not Prevent Cell Death Induced by Oncogenes, DNA Damage, or Bcl-2 Homologue Bak, J. Cell Biol. 215-227.

Mehlen, P., Schulze-Osthoff, K. \& Arrigo, A. P. (1996) Small stress proteins as novel regulators of apoptosis, J. Biol. Chem. 271, 16510-16514. 
Mignotte, B., Larcher, J. C., Zheng, D. Q., Esnault, C., Coulaud, D. \& Feunteun, J. (1990)

SV40 induced cellular immortalization : phenotypic changes associated with the loss of proliferative capacity in a conditionally immortalized cell line, Oncogene 5, 1529-1533.

Minn, A. J., Velez, P., Schendel, S. L., Liang, H., Muchmore, S. W., Fesik, S. W., Fill, M. \& Thompson, C. B. (1997) Bcl-x ${ }_{\mathrm{L}}$ forms an ion channel in synthetic lipid membranes, Nature 385, 353-357.

Mirkovic, N., Voehringer, D. W., Story, M. D., McConkey, D. J., McDonnell, T. J. \& Meyn, R. E. (1997) Resistance to radiation-induced apoptosis in Bcl-2-expressing cells is reversed by depleting cellular thiols, Oncogene 15, 1461-1470.

Muchmore, S. W., Sattler, M., Liang, H., Meadows, R. P., Harlan, J. E., Yoon, H. S., Nettesheim, D., Chang, B. S., Thompson, C. B., Wong, S. L., Ng, S. C. \& Fesik, S. W. (1996) X-ray and NMR structure of human $\mathrm{Bcl}_{\mathrm{L}}$, an inhibitor of programmed cell death, Nature 381, 335-341.

Myers, K. M., Fiskum, G., Liu, Y., Simmens, S. J., Bredesen, D. E. \& Murphy, A. N. (1995) Bcl-2 protects neural cells from cyanide/aglycemia-induced lipid oxidation, mitochondrial injury, and loss of viability, J. Neurochem. 65, 2432-2440. 
Nagata, S. (1997) Apoptosis by Death Factor, Cell 88, 355-365.

Nakai, M., Takeda, A., Cleary, M. L. \& Endo, T. (1993) The bcl-2 protein is inserted into the outer membrane but not into the inner membrane of rat liver mitochondria in vitro, Biochem. Biophys. Res. Commun. 196, 233-239.

Naumovski, L. \& Cleary, M. L. (1996) The p53-binding protein 53BP2 also interacts with Bcl-2 and impedes cell cycle progression at G2/M, Mol Cell Biol 16, 3884-3892.

Newmeyer, D. D., Farschon, D. M. \& Reed, J. C. (1994) Cell-free apoptosis in Xenopus egg extracts: inhibition by Bcl-2 and requirement for an organelle fraction enriched in mitochondria, Cell 79, 353-364.

Nguyen, M., Branton, P. E., Walton, P. A., Oltvai, Z. N., Korsmeyer, S. J. \& Shore, G. C. (1994) Role of membrane anchor domain of Bcl-2 in suppression of apoptosis caused by E1B-defective adenovirus, J. Biol. Chem. 269, 16521-16524.

Nguyen, M., Millar, D. G., Yong, V. W., Korsmeyer, S. J. \& Shore, G. C. (1993) Targeting of bcl-2 to the mitochondrial outer membrane by a COOH-Terminal signal anchor sequence, J. Biol. Chem. 268, 25265-25268. 
Nicholson, D. W. \& Thornberry, N. A. (1997) Caspases: killer proteases, Trends Biochem. Sci. 22, 299-306.

O'Donnell, V. B., Spycher, S. \& Azzi, A. (1995) Involvement of oxidants and oxidantgenerating enzyme(s) in tumour- necrosis-factor-alpha-mediated apoptosis: role for lipoxygenase pathway but not mitochondrial respiratory chain, Biochem J 310, 133-141.

Olivier, R., Otter, I., Monney, L., Wartmann, M. \& Borner, C. (1997) Bcl-2 does not require Raf kinase activity for its death-protective function, Biochem. J. 324, 75-83.

Oltvai, Z. N., Milliman, C. L. \& Korsmeyer, S. J. (1993) bcl-2 heterodimerizes in vivo with a conserved homolog, bax, that accelerates programmed cell death, Cell 74, 609619.

Paumen, M. B., Ishida, Y., Han, H., Muramatsu, M., Eguchi, Y., Tsujimoto, Y. \& Honjo, T. (1997) Direct interaction of the mitochondrial membrane protein carnitine palmitoyltransferase I with Bcl-2, Biochem. Biophys. Res. Commun. 231, 523-525.

Petit, P. X., Lecoeur, H., Zorn, E., Dauguet, C., Mignotte, B. \& Gougeon, M. L. (1995) Alterations in mitochondrial structure and function are early events of dexamethasoneinduced thymocytes apoptosis, J. Cell Biol. 130, 157-167. 
Petit, P. X., Susin, S. A., Zamzani, N., Mignotte, B. \& Kroemer, G. (1996) Mitochondria and programmed cell death: back to the future, FEBS lett. 396, 7-13.

Petronilli, V., Nicolli, A., Costantini, P., Colonna, R. \& Bernardi, P. (1994) Regulation of the permeability transition pore, a voltage-dependent mitochondrial channel inhibited by cyclosporin A., Biochem. Biophys. Acta 1187, 255-259.

Pinkus, R., Weiner, L. M. \& Daniel, V. (1996) Role of Oxidants and Antioxidants in the Induction of AP-1, NF-kB, and Glutathione S-Transferase Gene Expression., J. Biol. Chem. 271, 13422-13429.

Quillet-Mary, A., Jaffrezou, J. P., Mansat, V., Bordier, C., Naval, J. \& Laurent, G. (1997) Implication of mitochondrial hydrogen peroxide generation in ceramide- induced apoptosis, J. Biol. Chem. 272, 21388-21395.

Raff, M. C. (1992) Social control on cell survival and cell death, Nature 356, 397-400.

Raff, M. C., Barres, B. A., Burne, J. F., Coles, H. S., Ishizaki, Y. \& Jacobson, M. D. (1993) Programmed cell death and the control of cell survival: lessons from the nervous system, Science 262, 695-700. 
Ratan, R. R., Murphy, T. H. \& Baraban, J. M. (1994) Oxidative stress induces apoptosis in embryonic cortical neurons, J. Neurochem. 62, 376-379.

Reed, J. C. (1997) Double identity for proteins of the Bcl-2 family, Nature 387, 773-776.

Richter, C., Gogvadze, V., Laffranchi, R., Schlapbach, R., Schweizer, M., Suter, M., Walter, P. \& Yaffee, M. (1995) Oxidants in mitochondria: from physiology to diseases, Biochim Biophys Acta 1271, 67-74.

Ryan, J. J., Prochownik, E., Gottlieb, C. A., Apel, I. J., Merino, R., Nunez, G. \& Clarke, M. F. (1994) c-myc and bcl-2 modulate p53 function by altering p53 subcellular trafficking during the cell cycle, Proc. Natl. Acad. Sci. USA 91, 5878-5882.

Sandstrom, P. A. \& Buttke, T. M. (1993) Autocrine production of extracellular catalase prevents apoptosis of the human CEM T-cell line in serum-free medium, Proc. Natl. Acad. Sci. USA 90, 4708-4712.

Sato, N., Iwata, S., Nakamura, K., Hori, T., Mori, K. \& Yodoi, J. (1995) Thiol-Mediated Redox Regulation of Apoptosis. Possible roles of cellular thiols other than glutathione in T cell apoptosis, J. Immunol. 154, 3194-3203. 
Schendel, S. L., Xie, Z., Montal, M. O., Matsuyama, S., Montal, M. \& Reed, J. C. (1997)

Channel formation by antiapoptotic protein Bcl-2, Proc. Natl. Acad. Sci. USA 94, 51135118.

Schulz, G. E. (1986) Porins: general to specific, native to engineered passive pores, Curr. Op. Struct. Biol. 6, 485-490.

Schulze-Osthoff, K., Bakker, A. C., Vanhaesebroeck, B., Beyaert, R., Jacob, W. A. \& Fiers, W. (1992) Cytotoxic activity of tumor necrosis factor is mediated by early damage of mitochondrial functions. Evidence for the involvement of mitochondrial radical generation, J. Biol. Chem. 267, 5317-5323.

Schulze-Osthoff, K., Beyaert, R., Vandevoorde, V., Haegeman, G. \& Fiers, W. (1993) Depletion of the mitochondrial electron transport abrogates the cytotoxic and GeneInductive effects of TNF, EMBO J. 12, 3095-3104.

Schulze-Osthoff, K., Krammer, P. H. \& Droge, W. (1994a) Divergent signalling via APO-1/Fas and the TNF receptor, two homologous molecules involved in physiological cell death, EMBO J. 13, 4587-4596. 
Schulze-Osthoff, K., Walczak, H., Droge, W. \& Krammer, P. H. (1994b) Cell nucleus and DNA fragmentation are not required for apoptosis, J. Cell Biol. 127, 15-20.

Schwartz, L. M., Smith, S. W., Jones, M. E. E. \& Osborne, B. A. (1993) Do all programmed cell deaths occur via apoptosis?, Proc. Natl. Acad. Sci. USA 90, 980-984.

Sedlak, T. W., Oltvai, Z. N., Yang, E., Wang, K., Boise, L. H., Thompson, C. B. \& Korsmeyer, S. J. (1995) Multiple Bcl-2 family members demonstrate selective dimerizations with Bax, Proc. Natl. Acad. Sci. USA 92, 7834-7838.

Shaham, S. \& Horvitz, H. R. (1996) Developing Caenorhabditis elegans neurons may contain both cell-death protective and killer activities, Genes Dev. 10, 578-591.

Shibasaki, F., Kondo, E., Akagi, T. \& McKeon, F. (1997) Suppression of signalling through transcription factor NF-AT by interactions between calcineurin and Bcl-2, Nature 386, 728-731.

Shimizu, S., Eguchi, Y., Kosaka, H., Kamiike, W., Matsuda, H. \& Tsujimoto, Y. (1995) Prevention of hypoxia-induced cell death by Bcl-2 and Bcl-X ${ }_{\mathrm{L}}$, Nature 374, 811-813.

Sidoti-de Fraisse, C., Rincheval, V., Risler, Y., Mignotte, B. \& Vayssière, J. L. (1997) TNF- $\alpha$ activates at least two apoptotic signaling cascades, Soumis. 
Sies, H. (1991) Oxidative stress: from basic research to clinical application, Am. J. Med. 91, 31S-38S.

Skowronek, P., Haferkamp, O. \& Rodel, G. (1992) A fluorescence-microscopic and flow cytometric study of HeLa cells with an experimentally induced respiratory deficiency, Biochem. Biophys. Res. Commun. 187, 991-998.

Spector, M. S., Desnoyers, S., Hoeppner, D. J. \& Hengartner, M. O. (1997) Interaction between the C. elegans cell-death regulators CED-9 and CED-4., Nature 385, 653-656.

Steinman, H. M. (1995) The Bcl-2 oncoprotein functions as a pro-oxidant, J. Biol. Chem. $270,3487-3490$.

Steller, H. (1995) Mechanisms and genes of cellular suicide, Science 267, 1445-1449.

Susin, S. A., Zamzami, N., Castedo, M., Daugas, E., Wang, H. G., Geley, S., Fassy, F., Reed, J. C. \& Kroemer, G. (1997) The central executioner of apoptosis: multiple connections between protease activation and mitochondria in Fas/APO-1/CD95- and ceramide- induced apoptosis, J. Exp. Med. 186, 25-37. 
Susin, S. A., Zamzani, N., Castedo, M., Hirsh, T., Marchetti, P., Macho, A., Daugas, E., Geuskens, M. \& Kroemer, G. (1996) Bcl-2 inhibits the mitochondrial release of an apoptogenic protease, J. Exp. Med. 184, 1-11.

Szabo, I., Bathori, G., Wolff, D., Starc, T., Cola, C. \& Zoratti, M. (1995) The highconductance channel of porin-less yeast mitochondria, Biochim. Biophys. Acta 1235, 115125.

Takayama, S., Sato, T., Krajewski, S., Kochel, K., Irie, S., Millan, J. A. \& Reed, J. C. (1995) Cloning and functional analysis of BAG-1: a novel Bcl-2-binding protein with anti-cell death activity, Cell 80, 279-284.

Tan, E. M. (1994) Autoimmunity and Apoptosis, J. Exp. Med. 179, 1083-1086.

Tao, W., Kurschner, C. \& Morgan, J. I. (1997) Modulation of cell death in yeast by the Bcl-2 family of proteins, J. Biol. Chem. 272, 15547-15552.

Tyurina, Y. Y., Tyurin, V. A., Carta, G., Quinn, P. J., Schor, N. F. \& Kagan, V. E. (1997) Direct evidence for antioxidant effect of Bcl-2 in PC12 rat pheochromocytoma cells, Arch. Biochem. Biophys. 344, 413-423. 
Uckun, F. M., Tuelahlgren, L., Song, C. W., Waddick, K., Myers, D. E., Kirihara, J., Ledbetter, J. A. \& Schieven, G. L. (1992) Ionizing radiation stimulates unidentified Tyrosine-Specific protein kinases in human Lymphocyte-B precursors, triggering apoptosis and clonogenic cell death, Proc. Natl. Acad. Sci. USA 89, 9005-9009.

van den Dobbelsteen, D. J., Nobel, C. S. I., Schlegel, J., Cotgreave, I. A., Orrenius, S. \& Slater, A. F. G. (1996) Rapid and Specific Efflux of Reduced Glutathione during Apoptosis Induced by Anti-Fas/APO-1 Antibody, J. Biol. Chem. 271, 15420-15427.

Vaux, D. L., Haecker, G. \& Strasser, A. (1994) An Evolutionary Perspective on Apoptosis, Cell 76, 777-779.

Vayssière, J. L., Petit, P. X., Risler, Y. \& Mignotte, B. (1994) Commitment to apoptosis is associated with changes in mitochondrial biogenesis and activity in cell lines conditionally immortalized with Simian Virus 40, Proc. Natl. Acad. Sci. USA 91, 1175211756.

Veis, D. J., Sorenson, C. M., Shutter, J. R. \& Korsmeyer, S. J. (1993) Bcl-2-Deficient mice demonstrate fulminant lymphoid apoptosis, polycystic kidneys, and hypopigmented hair, Cell 75, 229-240. 
Wang, H., Rapp, U. R. \& Reed, J. C. (1996a) Bcl-2 Targets the Protein Kinase Raf-1 to Mitochondria, Cell 87, 629-638.

Wang, H. G., Miyashita, T., Takayama, S., Sato, T., Torigoe, T., Krajewski, S., Tanaka, S., Hovey, L. r., Troppmair, J., Rapp, U. R. \& Reed, J. C. (1994) Apoptosis regulation by interaction of Bcl-2 protein and Raf-1 kinase, Oncogene 9, 2751-2756.

Wang, H. G., Takayama, S., Rapp, U. R. \& Reed, J. C. (1996b) Bcl-2 interacting protein, BAG-1, binds to and activates the kinase Raf- 1, Proc. Natl. Acad. Sci. USA 93, 70637068.

Wang, X. \& Studzinski, G. P. (1997) Antiapoptotic action of 1,25-dihydroxyvitamin D3 is associated with increased iitochondrial MCL-1 and RAF-1 proteins and reduced release of cytochrome c, Exp. Cell. Res. 235, 210-217.

Weil, M., Jacobson, M. D., Coles, H. S. R., Davies, T. J., Gardner, R. L., Raff, K. D. \& Raff, M. C. (1996) Constitutive expression of the machinery for programmed cell death, J. Cell Biol. 133, 1053-1059.

Welburn, S. C., Dale, C., Ellis, D., Beecroft, R. \& Pearson, T. W. (1996) Apoptosis in procyclic Trypanosoma brucei rhodesiense in vitro, Cell Death Differ. 3, 229-236. 
Williams, G. T. (1991) Programmed cell death : apoptosis and oncogenesis, Cell 65, 1097-1098.

Wolter, K. G., Hsu, Y. T., Smith, C. L., Nechushtan, A., Xi, X. G. \& Youle, R. J. (1997) Movement of Bax from the Cytosol to Mitochondria during Apoptosis, J. Cell. Biol. 139, $1281-1292$.

Wolvetang, E. J., Johnson, K. L., Krauer, K., Ralph, S. J. \& Linnane, A. W. (1994) Mitochondrial respiratory chain inhibitors induce apoptosis, FEBS Lett. 339, 40-44.

Wong, G. H. W., Elwell, J. H., Oberley, L. W. \& Goeddel, D. V. (1989) Manganous superoxide dismutase is essential for cellular resistance to cytotoxicity of tumor necrosis factor, Cell 58, 923-931.

Wu, D., Wallen, H. D. \& Nunez, G. (1997) Interaction and regulation of subcellular localization of CED-4 by CED-9, Science 275, 1126-1129.

Yang, J., Liu, X., Bhalla, K., Kim, C. N., Ibrado, A. M., Cai, J., Peng, T. I., Jones, D. P. \& Wang, X. (1997) Prevention of apoptosis by Bcl-2: release of cytochrome c from mitochondria blocked, Science 275, 1129-1132. 
Yang, T., Kozopas, K. M. \& Craig, R. W. (1995) The intracellular distribution and pattern of expression of Mcl-1 overlap with, but are not identical to, those of Bcl-2, J. Cell Biol. $128,1173-1184$.

Yuan, J. Y., Shaham, S., Ledoux, S., Ellis, H. M. \& Horvitz, H. R. (1993) The C. elegans cell death gene ced-3 encodes a protein similar to mammalian interleukin-1 betaconverting enzyme, Cell 75, 641-652.

Zamzami, N., Marchetti, P., Castedo, M., Decaudin, D., Macho, A., Petit, P. X., Mignotte, B. \& Kroemer, G. (1995a) Sequential reduction of mitochondrial transmembrane potential and generation of reactive oxygen species in early programmed cell death, $J$. Exp. Med. 182, 367-377.

Zamzami, N., Marchetti, P., Castedo, M., Hirsch, T., Susin, S. A., Masse, B. \& Kroemer, G. (1996a) Inhibitors of permeability transition interfere with the disruption of the mitochondrial transmembrane potential during apoptosis, FEBS Lett. 384, 53-57.

Zamzami, N., Marchetti, P., Castedo, M., Zanin, C., Vayssière, J. L., Petit, P. X. \& Kroemer, G. (1995b) Reduction in mitochondrial potential constitutes an early irreversible step of programmed lymphocyte death in vivo, J. Exp. Med. 181, 1661-1672. 
Zamzami, N., Susin, S. A., Marchetti, P., Hirsch, T., Gomez-Monterrey, I., Castedo, M. \& Kroemer, G. (1996b) Mitochondrial control of nuclear apoptosis, J. Exp. Med. 183, 1533-1544.

Zhong, L. T., Sarafian, T., Kane, D. J., Charles, A. C., Mah, S. P., Edwards, R. H. \& Bredesen, D. E. (1993) bcl-2 inhibits death of central neural cells induced by multiple agents, Proc. Natl. Acad. Sci. USA 90, 4533-4537.

Zhu, W., Cowie, A., Wasfy, G. W., Penn, L. Z., Leber, B. \& Andrews, D. W. (1996) Bcl2 mutants with restricted subcellular location reveal spatially distinct pathways for apoptosis in different cell types, EMBO J. 15, 4130-4141.

Zou, H., Henzel, W. J., Liu, X., Lutschg, A. \& Wang, X. (1997) Apaf-1, a human protein homologous to C. elegans CED-4, participates in cytochrome c-dependent activation of caspase-3, Cell 90, 405-413. 


\section{$\underline{\text { Legends to figures }}$}

Figure 1. Simplified model of events occurring during apoptosis

Numerous signals can lead to apoptosis. The induction pathways seem to converge to events involving mitochondria. Proteins of the Bcl-2 act on mitochondria at least at two levels: regulation of ionic exchanges through transmembrane channels, and, anchorage to the mitochondrial membrane of pro-apoptotic proteins capable of activating caspases.

Figure 2. CED-9 regulates the intracellular localization of CED-4/CED-3 complexes

In C. elegans, CED-9 might maintain CED-4/CED-3 complexes at the level of intracellular membranes by its simultaneous binding to mitochondrial membrane and CED-4. Similarly, in mammals, Bcl- $\mathrm{X}_{\mathrm{L}}$ might anchor Apaf-1/caspase complexes and keep them in an inactive state. The dissociation of the Bcl- $\mathrm{X}_{\mathrm{L}} / \mathrm{Apaf}-1$ interaction by Bax (or other proapoptotic Bcl-2s) might lead to the activation of cytoplasmic and nuclear caspases.

Figure 3. Mechanism giving rise to endosymbiosis and apoptosis control 
The endosymbiontic bacterium might have contained molecules lethal for the host in the future mitochondrial matrix or in the intermembrane space. In this context, the host cell would have been constrained to control the exchanges between the mitochondria and the cytosol.

In unicellular eukaryotes, damage to mitochondrial membranes might provoke the release of these molecules in the cytoplasm. Metazoan might have developed means to control these events. 


\section{C. elegans Mammals}

CED-3 Activation caspases: caspase-1 (ICE), -4 (ICH-2), -6 (Mch2), -8 (MACH/FLICE)...

Execution caspases: caspase-2 (ICH-1), -3 (CPP32), -4 (ICH-2), -7

(ICE-LAP3)...

CED-4 Apaf-1

CED-9 Anti-apoptotic: Bcl-2, Bcl-x $\mathrm{x}_{\mathrm{L}}$, Bcl-w, Bfl-1, Brag-1, Mcl-1, A1, NR13...

Pro-apoptotic: Bax, Bak, Bcl-xs, Bad, Bik, Hrk...

Table I: Programmed cell death in nematodes and mammals is controlled by homologous

proteins. Mammalian caspases act either during the activation or the execution phase of PCD (Nicholson and Thornberry, 1997). Recently, a CED-4 homologue has been identified in human cells (Hofmann et al., 1997; Zou et al., 1997). In mammals some members of the Bcl-2 related proteins are death antagonists while other are death agonists. 
For a recent review on the structure-function relations of Bcl-2 related proteins see (Kroemer, 1997b). 


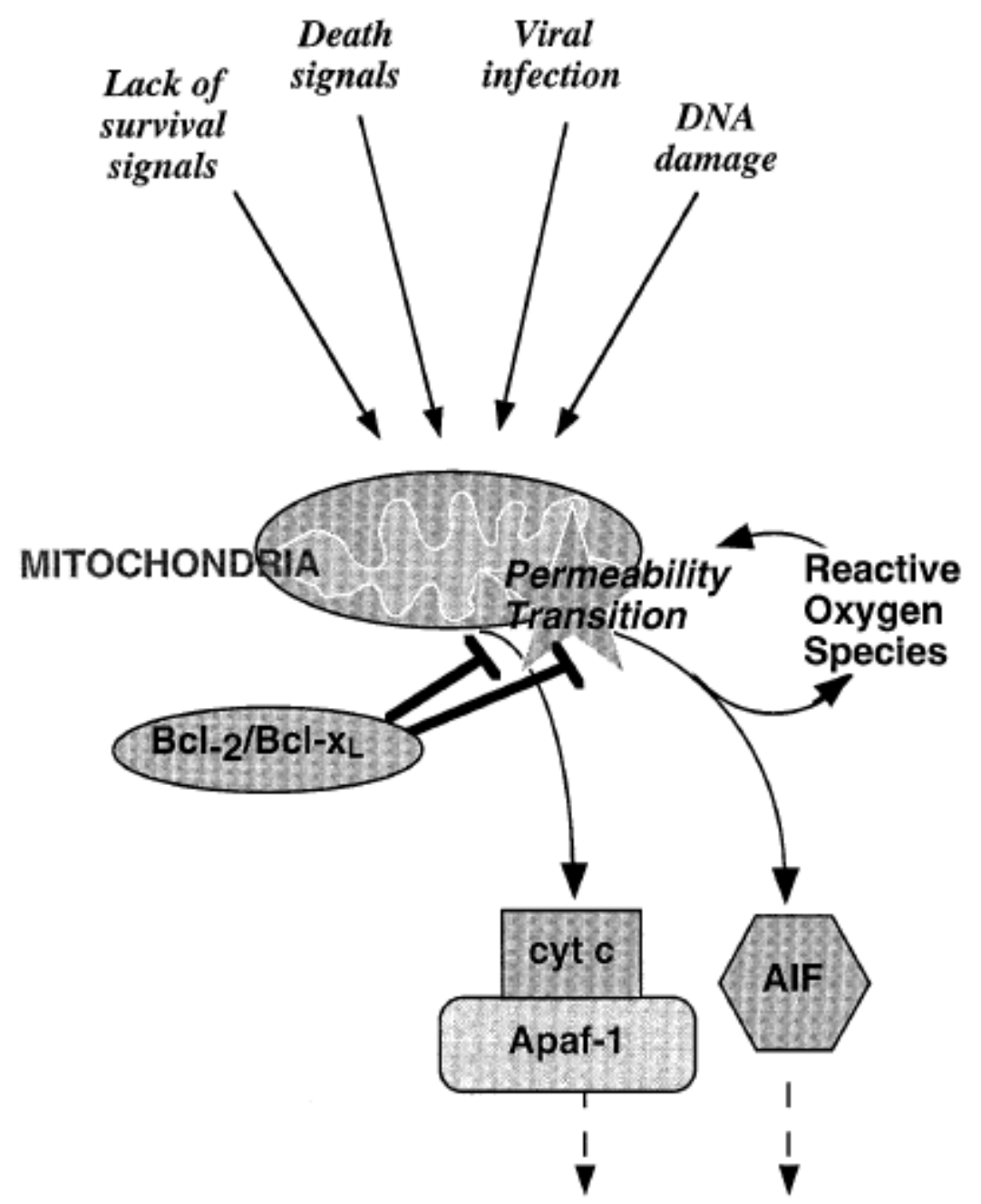

Execution caspases activation

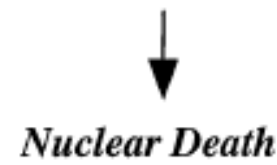

Fig 1 


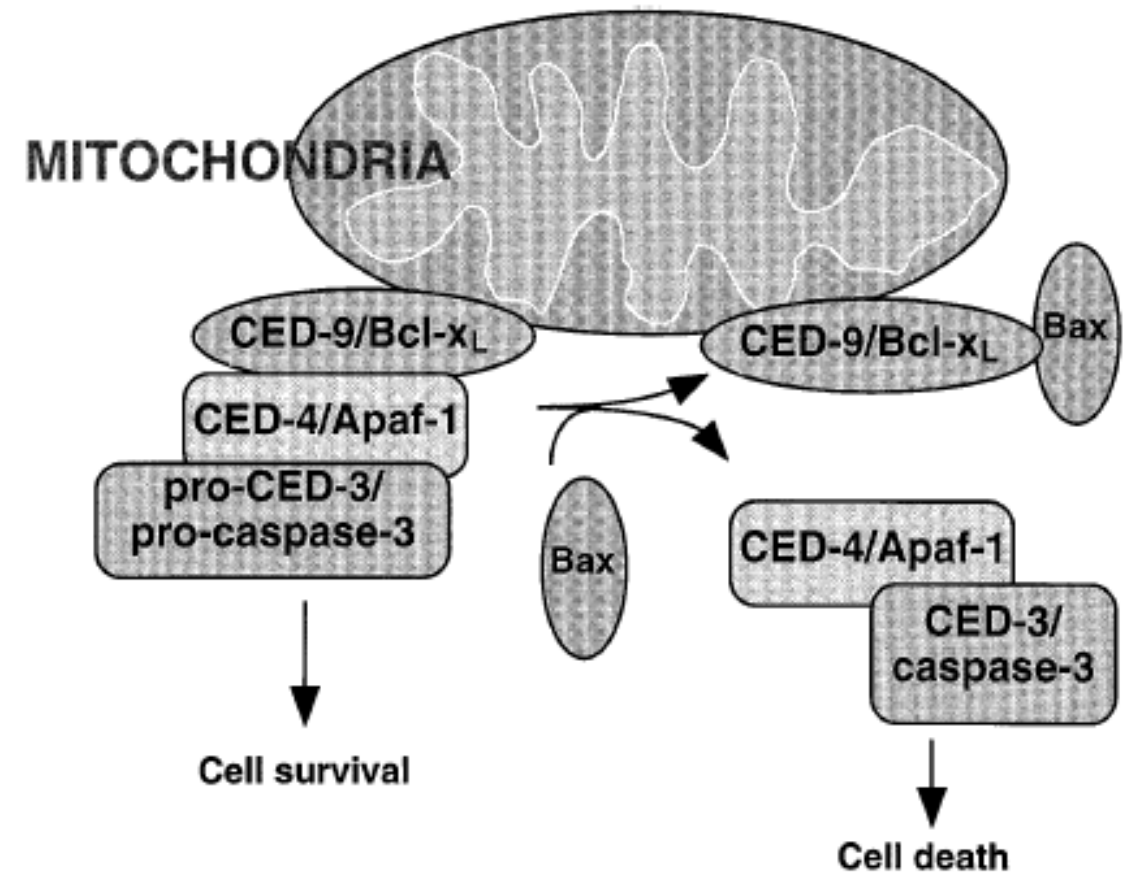

Fig 2 